\title{
Valoración patrimonial del Parque- Monumento, Trujillo, Colombia: memorial democrático al servicio de una comunidad de memoria*
}

DOI: https://doi.org/10.18046/recs.i28.3267

\author{
Patrimonial Valuation of the Parque-Monumento \\ in Trujillo, Colombia: Democratic Memorial at the Service \\ of a Community of Memory \\ Valorização patrimonial do Parque-Monumento, \\ Trujillo-Colômbia:memorial-democrático ao serviço \\ de uma comunidade de memoria
}

Edward Garzón-Ochoa ${ }^{* *}$

Universidad Pedagógica y Tecnológica de Colombia (Tunja)

\footnotetext{
* Este artículo deriva de la tesis de maestría titulada "Patrimonio de la memoria: valoración patrimonial de Parque-Monumento, Trujillo-Colombia”, elaborada en el marco de la Maestría en Patrimonio Cultural de la Universidad Pedagógica y Tecnológica de Colombia, bajo la dirección de la doctora María Angélica Garzón. Proyecto SGI 2428, financiado por la Vicerrectoría de Investigaciones de la UPTC. Artículo de investigación recibido el 31.07.2018 y aceptado el o8.04.2019.

** Magíster en Patrimonio Cultural, Universidad Pedagógica y Tecnológica de Colombia; Grupo Interdisciplinario de Investigaciones Arqueológicas e Históricas. Correo electrónico: ed.159@hotmail.com ORCID: https://orcid.org/oooo$0002-0032-8327$
} 


\section{Cómo citar/How to cite}

Garzón-Ochoa, Edward (2019). Valoración patrimonial del Parque-Monumento, Trujillo, Colombia: memorial democrático al servicio de una comunidad de memoria. Revista CS, 28, 87-124. https://doi.org/10.18046/recs.i28.3267 
Resumen

Abstract

Resumo

El boom de la memoria dio paso a la construcción y proliferación de un patrimonio memorial que refleja material y simbólicamente la identidad de comunidades afectadas por la violencia. En el municipio de Trujillo, Colombia, después de la masacre perpetrada entre 1986-1994, se planteó, como medida de reparación, la construcción del Parque-Monumento; memorial democrático creado con la intención de tramitar el dolor, exigir justicia y verdad, dignificar y empoderar a las víctimas, e hilar los lazos sociales quebrantados por la violencia. Sin embargo, el lugar ha sido objeto de críticas $\mathrm{e}$, incluso, ha sufrido varios atentados en los últimos años.

En este sentido, se realizó una valoración patrimonial donde se describen las diferentes percepciones que tienen los habitantes del municipio respecto al Parque-Monumento. En el texto, se hace un recorrido por los procesos de monumentalización, hasta llegar a los memoriales democráticos y situar, de este modo, el contexto histórico y social que dio origen al Parque-Monumento. Después, se analizan las valoraciones positivas provenientes de los trabajos de la memoria, parte fundamental de la significación cultural del sitio, que, a través de las prácticas, usos, asociaciones y funciones consolidan lazos de apego, pertenencia e identidad. Por último, se describen los valores negativos o antivalores que provienen de personas externas a la comunidad de memoria.

PALABRAS CLAVE:

valoración patrimonial, memorial democrático, comunidad de memoria, pedagogía de la memoria

The memory boom gave way to the construction and proliferation of a memorial heritage that materially and symbolically reflects the identity of the communities affected by violence. In Trujillo, Colombia, after the 1986-1994 massacre, the construction of the Parque-Monumento was proposed as a reparation measure; a democratic memorial, created with the intention of dealing with pain, demanding justice and truth, dignifying and empowering the victims, and spinning the social ties broken by violence. However, the place has been the target of criticism and has even suffered several attacks in recent years. In this sense, a patrimonial valuation was carried out describing the different percep- 
tions that the inhabitants of the municipality have of the Parque-Monumento. In the text, the processes of making it a monument, up to the democratic memorials, are reviewed, and in this way, it provides the historical and social context that gave rise to the Parque-Monumento. Afterward, the positive valuations coming from the works of memory, a fundamental part of the cultural significance of the site, are analysed, which, through practices, uses, associations, and functions consolidate ties of attachment, belonging, and identity. Finally, the negative values or anti-values that come from people outside the community of memory are described.

\section{KEYWORDS:}

Patrimonial Valuation, Democratic Memorial, Community of Memory, Pedagogy of Memory

O boom da memória deu lugar à construção e proliferação de uma herança memorial que materialmente e simbolicamente reflete a identidade das comunidades afetadas pela violência. Em Trujillo-Colômbia, após o massacre perpetrado entre 1986n e 1994, a construção do Parque-Monumento; memorial-democrático criado com a intenção de processar a dor, exigir justiça e verdade; dignificar e empoderar vítimas e girar laços sociais quebrados pela violência. No entanto, o local tem sido criticado e sofreu vários ataques nos últimos anos.

Neste sentido, foi realizada uma avaliação patrimonial onde descrevem-se as diferentes percepções que os habitantes do município têm sobre o Parque-Monumento. No texto, percorre-se o processo de monumentalização, até chegar aos monumentos democráticos, colocando assim o contexto histórico e social que deu origem ao Parque-Monumento. Posteriormente, analisam-se as avaliações positivas provenientes dos trabalhos de memória, parte fundamental do significado cultural do local, que, por meio de práticas, usos, associações e funções, consolida laços de apego, pertença e identidade. Finalmente, descrevem-se os valores negativos que vêm de pessoas fora da comunidade de memória.

\section{PALAVRAS-CHAVE:}

valoração patrimonial, memorial-democrático, comunidade de memória, pedagogia da memória 


\section{Introducción}

A través de monumentos, memoriales y marcas territoriales, organizaciones sociales e instituciones oficiales y no oficiales han monumentalizado la violencia, huellas dejadas en el espacio público para advertir acerca de un hecho trágico, un personaje heroico o una fecha importante. Estas obras han sido utilizadas para narrar particularidades de la violencia, como ¿qué pasó?, ¿por qué pasó?, ¿cómo pasó?, ¿quiénes fueron las víctimas? y ¿quiénes fueron los victimarios?

Estas representaciones atraviesan por una serie de tensiones, como el abandono, el olvido, la osificación o la destrucción; sin embargo, alrededor del mundo, artistas, familiares de víctimas y grupos de derechos humanos han transformado las dinámicas de estos lugares, generando relaciones de identidad, apego y apropiación ${ }^{1}$. Allí, los emprendedores de la memoria reconstruyen el tejido social quebrantado por la violencia, enseñan acerca de lo sucedido, tramitan duelos y generan mecanismos para garantizar la no repetición de los hechos trágicos.

En este panorama, se enmarca el Parque-Monumento en Trujillo, Colombia; lugar pensado, construido y conservado por una comunidad de memoria que, a través de sus experiencias, recuerdos y narrativas significan positivamente el memorial; no obstante, sus esfuerzos se ven soslayados, cuestionados, silenciados y violentados por agentes externos que promueven valores negativos o antivalores, generando una serie de tensiones que dificultan las prácticas de recordación. Así, el objetivo de este artículo es identificar, analizar y describir los valores positivos y negativos que emanan del Parque-Monumento.

Ahora bien, los monumentos, memoriales y marcas territoriales se enmarcan en los debates contemporáneos de la memoria, más aún, en las políticas de la memoria que tienen por objetivo difundir o consolidar de manera pública una determinada interpretación de un acontecimiento que puede ser oficial o no. En este sentido, una sociedad dividida por la violencia no puede visualizar el pasado desde una sola perspectiva; por lo tanto, casi todos los proyectos de memorialización ocurren en escenarios de debate y confrontación entre diferentes significaciones que incluyen

1. Para el geógrafo Yi-Fu Tuan (1977), el apego es un instinto de pertenencia y apropiación, producto de la dimensión simbólica del habitar humano. El antropólogo Calos Mario Yory define las relaciones de apego a partir de las topofilias, concepto utilizado para analizar los valores humanos, los lazos emocionales y la naturaleza de los lugares. Estas tres relaciones determinan los sentidos de pertenencia y las formas de "ser-en-el-mundo" (Yory, 2002; 2003). 
la posibilidad de la indiferencia y el olvido². Así, memoriales públicos como el Parque-Monumento se materializan en un campo de batalla que confronta el pasado y el presente a razón del futuro, porque "generalmente, no hay un proyecto de rememoración explícitamente formulado, sino que el devenir de la acción humana incorpora nuevos rituales y nuevos significados al ya cargado 'lugar'” (Jelin; Langland, 2003:5).

\section{Monumentalizando la violencia}

Andreas Huyssen (2002), en su texto En busca del tiempo futuro, cultura y memoria en tiempo de globalización, reconoce como fenómeno contemporáneo el boom de la memoria; fenómeno emergente a partir del auge de estudios culturales y políticos referentes a la memoria, en un tiempo donde la amnesia generalizada, el Alzheimer colectivo y la memoria deficiente atemoriza ámbitos políticos, académicos y, particularmente, del patrimonio cultural (Achugar, 2003; 2004).

En Europa, el boom de la memoria tiene como referente narrativo el Holocausto, tropo universal utilizado como prisma en los procesos de construcción y reconstrucción del pasado3 (Huyssen, 2002; 2014). Los hechos trágicos, dolorosos y vergonzosos descubiertos al finalizar la segunda Guerra Mundial avivaron numerosos debates en torno al deber y la necesidad de recordar; en un giro hacia el pasado que asestó la discusión en ámbitos narrativos, políticos y éticos orientados por la necesidad de saldar cuentas, exigir justica, avalar proyectos democratizadores y restablecer el tejido social quebrantado por la violencia (Garzón, 2015).

En Latinoamérica, y particularmente en el Cono Sur, los procesos de democratización posteriores a las dictaduras militares fueron los referentes narrativos que dieron sentido al boom de la memoria. En períodos transicionales, países como Argentina, Chile y Uruguay realizaron multiplicidad de estudios políticos y culturales,

2. Las percepciones, valoraciones y apropiaciones de estos lugares son producto de las territorialidades cambiantes y conflictivas: "la territorialidad se asocia con apropiación y ésta con identidad y afectividad espacial, que se combinan definiendo territorios apropiados de derecho, de hecho y afectivamente" (Montañez; Delgado, 1998: 124).

3. La memoria se constituye en un campo conflictivo que pone en pugna las interpretaciones del pasado, los significados de sociedad y los futuros posibles (Piper, 2009). Así, el deber de recordar es una característica propia del siglo XX, que asume, como punto de partida, las reflexiones en torno a la segunda Guerra Mundial (Huyssen, 2002; Ricoeur, 2008). En este sentido, el hito del Holocausto adquiere relevancia como referente de análisis de nuevos problemas sociales, como "los procesos decoloniales adelantados después de la caída del muro de Berlín, el papel de los movimientos sociales que reclaman la reescritura de pasados recientes, la consolidación de regímenes democráticos en América Latina, el reconocimiento de poblaciones víctimas de diversos conflictos y de la memoria como un derecho (...)" (Garzón, 2015:121). 
orientados por el deber de hacer justicia mediante el recuerdo, dialogar acerca de lo sucedido y fomentar valores democráticos para reconstruir las sociedades devastadas por la violencia (Allier; Crezel, 2015; Barbuto, 2012; Bickford; Brett; Ríos; Ševčenko, 2007; Fabri, 2013).

El boom de la memoria se ha manifestado en la producción cultural de objetos para recordar y conmemorar eventos del pasado ${ }^{4}$, tales como audiovisuales, publicaciones de memorias personales, novelas, investigaciones académicas, obras artísticas y, con mayor frecuencia, en la memorialización, es decir, la construcción de museos, monumentos, centros y casas de la memoria; espacios públicos que apelan al recuerdo, y homenaje de las víctimas en un ejercicio de reflexión, comunicación y difusión (Bickford et al., 2007; Dogliani, 2009; Martínez, 2012; Mora, 2013).

Los monumentos son las representaciones simbólicas más utilizadas en los procesos de memorialización. La palabra monumento deriva del latín monumentum, que alude al ejercicio de recordar, intención de los seres humanos por perpetuar y contemplar, en un tiempo diferente, la grandiosidad de un personaje o la magnitud de un hecho histórico (Choay, 2007; Lourés, 2001). Existen diferentes tipos de monumentos; sin embargo, los históricos y democráticos son los más distintivos.

Los monumentos históricos encarnan el locus naturalizador de instituciones con el poder político y mediático de representar un pasado ancestral, originario, legítimo y difícil de cuestionar por su prestigio simbólico (García-Canclini, 1992; Young, 200o). Por lo general, los Estados utilizan estas representaciones simbólicas para glorificar, enorgullecer y representar una historia oficial; memoria fuerte que oculta las narrativas "de aquellos que no tienen el poder de representarse o ser representados" (Achugar, 2004: 133). En este sentido, la sacralidad de los monumentos no deja espacios para la participación de las comunidades, por el contrario, estas representaciones son observadas, y referencias desde una óptica horizontal que dista de las dinámicas sociales donde se inscriben (Perichi, 2011).

No obstante, colectivos sociales, académicos y artísticos han rechazado los sentidos de permanencia o eternidad que encarnan los monumentos históricos, originando corrientes contramonumentalistas y antimonumentalistas, que cuestionan fuertemente la monumentalización hegemónica. Estas inclinaciones representan las memorias débiles, subalternas o subterráneas ${ }^{5}$, que distan de las representaciones

4. El boom de la memoria ha generado un culto, un abuso o una posible obsesión por el pasado que se convierte en un fenómeno antitético y problemático que va en contravía de la necesidad inexorable de olvidar (Ricoeur, 2008; Rieff, 2017; Todorov, 2000).

5. En Trujillo, como en otras partes del país, la persistencia del conflicto armado o la negación del mismo debilita las narrativas que emprenden familiares de víctimas y grupos de derechos humanos. Así, el concepto de memorias débiles o subterráneas adquiere relevancia en estos contextos, donde instituciones 
tradicionales, parcializadas, limitadas y limitantes de los hechos históricos (Saldarriaga, 1998; Young, 2000). La desidia y el desapego entre monumento histórico y comunidad se expresa a partir de la sustitución de significados, el olvido, la destrucción o la preservación, en su forma más osificada, como mito o cliché (Achugar, 2003; Choay, 2007; Huyssen, 2002; Jelin; Langland, 2003).

Ahora bien, con los procesos de democratización adelantados en Europa y Latinoamérica, se forjaron memoriales democráticos, representaciones simbólicas que no vanaglorian o idealizan los triunfos del Estado; por el contrario, reflexionan, reconocen, comunican y condenan discontinuidades históricas, tales como represiones, discriminaciones, persecuciones y exterminios (Achugar, 2003; Brodsky, 2012; Guixé, 2007; Sierra, 2014). Estas representaciones simbólicas son pensadas y construidas de manera vertical, lo que evidencia un continuo crecimiento en la gestión, conservación y proyección de estos lugares. Por lo general, estas producciones culturales se enmarcan en una memoria ejemplar, que reflexiona acerca de las injusticias cometidas en el pasado con relación presente (Todorov, 2000: 18).

En Alemania, placas informativas, obras plásticas, centros de información, recorridos e itinerarios hacen parte de los sistemas de memoria erigidos por el Estado, pero, en su mayoría, cuestionados e intervenidos por artistas, familiares de víctimas y grupos de derechos humanos. La memoria del Holocausto se ha convertido en parte viva y presente de los alemanes a nivel individual y colectivo, estas representaciones simbólicas buscan reflexionar, cuestionar y aceptar el pasado trágico y adverso de este suceso histórico ${ }^{6}$ (Young, 200o; Brodsky, 2012).

En Latinoamérica, Argentina y Chile fueron los primeros países en construir memoriales democráticos ${ }^{7}$, consolidando una cultura memorística que niega, ro-

con poder utilizan diferentes mecanismos para ocultar los trabajos de la memoria (Pollak, 2006). En palabras de Enzo Traverso, "hay memorias oficiales alimentadas por instituciones, incluso Estados, y memorias subterráneas, escondidas o prohibidas, la 'visibilidad' y el reconocimiento de una memoria dependen, también, de la fuerza de quienes la portan. Dicho de otra manera, hay memorias 'fuertes' y memorias 'débiles'” (Traverso, 2007: 48).

6. Estos son algunos de los referentes de memorialización en Alemania: Proyecto Siete Signos Artísticos (Berlín-1996), Monumento al Barrio Bávaro (Berlín-1993), Monumento de la Estación Ferroviaria (Berlín-Grunewald 1953), y Memorial de la Resistencia Alemana (Berlín-1954). Por último, es necesario reconocer las "Stolpersteine", del artista Gunter Deming, 45 ooo placas doradas incrustadas en el suelo, construidas manualmente en un ejercicio de reflexión y dignificación de las víctimas: "tropiece... mire... y recuerde a sus vecinos".

7. Memoriales construidos en Chile después de la dictadura militar: Parque por la Paz y Museo Villa Grimaldi (1994); Memorial del Detenido Desaparecido y Ejecutado Político (1994); Paine, un lugar para la memoria (2008); Monumento a las Mujeres Víctimas de la Represión: Mujeres en la Memoria (2008); y las Sillas: un Lugar para la Memoria de Natio, Parada y Guerrero (2006). Memoriales construidos en Argentina 
tundamente, las versiones contadas por los militares, proceso que refleja una verdad pública indudable e indeleble sobre lo ocurrido (Raggio, 2017). En estos países, el compromiso estatal ha sido exiguo, dificultando los procesos de verdad, justicia y reparación. Allí, los trabajos de la memoria son emprendidos, principalmente, por sobrevivientes, familiares de desaparecidos y organismos de derechos humanos que, a través de movilizaciones activas, logran transformar los centros de represión en vehículos para la memoria, cargados de sentidos que invitan a la reflexión y acción sobre el presente ${ }^{8}$ (Allier; Crezel, 2015; Brodsky, 2012; Fernández, 2015; Instituto de Políticas Públicas en Derechos Humanos del Mercosur (IPPDH), 2012; Jelin; Langland, 2003; Messina, 2011).

El boom de la memoria no es ajeno a la historia reciente de Colombia. Las diferentes olas de violencia sistemática que han enlutado al país son un referente en los procesos de memorialización, puesto que las actuaciones violentas generadas a lo largo y ancho del territorio nacional han dejado huellas imborrables, representadas en monumentos, memoriales y marcas territoriales 9 . A diferencia de los países que sufrieron las dictaduras del Cono Sur, en Colombia la violencia continúa, complejizando aún más los trabajos de la memoria (Jaramillo, 2015; Marín, 2011). No obstante, familiares de víctimas y colectivos de derechos humanos han buscado mecanismos para narrar su pasado, haciéndolo público a través de lugares que se piensan, construyen y reconstruyen de manera colectiva, modificando los imaginarios que alimentan la violencia (Comisión Nacional de Reconciliación y Reparación (CNRR), 2009). Estos lugares atestiguan una serie de tensiones que resultan de los cuestio-

después de la dictadura militar: el Museo de la Memoria de Rosario (2010), la Escuela de Mecánica de la Armada (Ex Esma-2004), Club Atlético (2014), la Casa Virrey Ceballos, el Olimpo (2004), el Parque a la Memoria (1998) y la Escuelita Famaillá (2012), sitios que han sido señalados, estudiados, demarcados y recuperados por familiares de víctimas y defensores de derechos humanos.

8. En relación a los procesos de memorialización, el Instituto de Políticas Públicas en Derechos Humanos del Mercosur, IPPDH, señala lo siguiente: "Tras el advenimiento de la democracia en los países del Cono Sur, el movimiento de derechos humanos, y sobre todo los familiares de las víctimas, han proclamado la creación de sitios de memoria. La acción de colocar cruces, placas o flores en distintos lugares por donde las víctimas dejaron sus huellas, los ha convertido en sitios de duelo y reparación. También se impulsó la creación de monumentos a las víctimas y de sitios en lugares vinculados con la resistencia a la represión" (IPPDH, 2012: 14).

9. Para la abogada Yolanda Sierra (2014), los alcances y las proyecciones de las representaciones simbólicas se determinan a partir de la procedencia de la obra; en este sentido: "el fin del Estado es reparar a las víctimas y contribuir con la garantía de no repetición; mientras que el fin de los artistas es manifestar la sensibilidad en relación con un tema específico que les interesa abordar; y para las víctimas, son mecanismos de resistencia y denuncia que permiten pasar del trauma individual a la conformación de sujetos colectivos con capacidad de incidir en las condiciones sociales que generan la violación a sus derechos humanos" (Sierra 2014: 77). 
namientos propios de las políticas de la memoria, a mencionar: ¿qué representar?, ¿a quién representar?, ¿para qué representar?, ¿cómo representar?, ¿quiénes deben o pueden participar en la gestión y administración de estos espacios? y ¿cuál es el grado de tolerancia y respeto de los habitantes frente a la representación simbólica?

De acuerdo a estos interrogantes, y tomando como referencia los procesos de monumentalización que se vienen adelantando en Colombia a propósito del deber de memoria y la necesidad de reparar a poblaciones víctimas del conflicto armado, vale la pena preguntarse: ¿necesita una sociedad fuertemente golpeada y marcada por la violencia y en tránsito hacia el post-conflicto monumentos? y, si los necesita, ¿de qué tipo? Para resolver estos cuestionamientos, se realizó un acercamiento etnográfico al Parque-Monumento en Trujillo, Colombia. Lo anterior, con el fin de reflexionar acerca de los procesos de monumentalización, sus características y dimensiones, las memorias que moviliza y las tensiones en las que se inscribe, en particular, aquellos memoriales erigidos en honor a las víctimas del conflicto armado como forma de recordación, dignificación y reparación comunitaria.

El Parque-Monumento es un lugar habitado ${ }^{10}$, por lo tanto, se liga, esencialmente, a las actividades cotidianas y a los espacios de rutina que representan el sentir de las víctimas. En palabras de Jelin y Langland (2003), el lugar es producto de "la agencia y la voluntad humana”. Así, durante el proceso de investigación se profundizó en torno a las maneras como es habitado el Parque-Monumento; por lo tanto, se realizaron diferentes recorridos con el objetivo de analizar las funciones, los usos y las asociaciones de objetos, tales como artesanías, pinturas, fotografías y esculturas.

A través de entrevistas conversacionales en situaciones naturales, familiares de víctimas, defensores de derechos humanos y visitantes describieron la naturaleza de los objetos; de ahí, se desprendieron valores humanos y lazos emocionales que fueron analizados, metodológicamente, bajo los principios expuestos por la teoría fundamentada de Strauss y Corbin (2002). En este sentido, el trabajo de campo se basó en la observación participante, en la elaboración y aplicación de entrevistas semiestructuradas y en el uso de la cartografía social (Espinosa; Rubio; Uribe, 2013).

Instituciones estatales, sectores académicos, grupos religiosos y organizaciones sociales han descrito e interpretado la masacre de Trujillo desde diversos enfoques

10. En 2016, 2017 y 2018 se realizaron diferentes visitas al Parque-Monumento, al observar los cambios estéticos, simbólicos, físicos y comunicativos se consideró necesario identificar los modos de habitar, ser y estar de familiares de víctimas, grupos de derechos humanos y visitantes. Así, emerge la noción del lugar habitado, es decir, un lugar en uso, donde se establecen relaciones a partir de las marcas o huellas, lugar cargado de sentidos y significados donde se construyen apegos, apropiaciones e identidades (Cuervo, 20O2; Heidegger, 2014; Yory, 2002; 2003). Por este motivo, fue pertinente hacer uso de la cartografía social, herramienta que posibilitó la interpretación del espacio como factor de identidad e interacción, “siempre disponible y dispuesto para convertirse en lugar, para ser construido" (Espinosa et al., 2013: 16). 
y con diversos objetivos; estas investigaciones se han plasmado a través de libros, artículos académicos, tesis de grado, informes, biografías, cartillas, videos, panfletos y representaciones simbólicas, como murales, esculturas, fotografías y pinturas. En este sentido, y con el fin de acotar la investigación, se recolectaron documentos provenientes de tres fuentes: los archivos sistematizados por AFAVIT ${ }^{11}$, informes oficiales y textos académicos. Estos documentos fueron codificados y conceptualizados en una base de datos, para luego ser entretejidos con las percepciones que los habitantes del municipio tienen del Parque-Monumento (Mills, 1993).

Esta fase de la investigación se denominó codificación abierta (open coding), proceso que arrojó una serie de códigos que fueron contrastados con entrevistas realizadas a familiares de víctimas, defensores de derechos humanos, visitantes, comerciantes, políticos y grupos religiosos, entre otros. Así, documentos, entrevistas, memos, observaciones y notas de campo se organizaron, relacionaron y codificaron en matrices de Excel, agrupadas según temas, códigos y conceptos de mayor relevancia. En seguida, se realizó una "comparación constante" de la información obtenida, con el fin de analizar similitudes, diferencias y grado de consistencia de los datos. Este momento de la investigación se denominó "paradigma de la codificación" (coding paradigm), proceso mediante el cual se jerarquizaron y relacionaron las categorías con sus condiciones, interacciones, estrategias/tácticas y consecuencias (Strauss; Corbin, 2002). Por último, se plantearon respuestas provisionales, para luego formular las categorías centrales expuestas en el siguiente texto.

Así, entre dibujos, documentos, entrevistas, planos y recorridos, emergieron, paulatinamente, las valoraciones que giran en torno al Parque-Monumento. Entre 2016, 2017 y 2018, se realizaron, aproximadamente, 53 entrevistas que fueron codificadas, relacionadas y analizadas bajo diversas matrices. Durante este proceso, se entrevistaron líderes y acompañantes de la asociación, por lo general, a través de un trabajo intergeneracional, es decir, se entrevistaron niños, jóvenes, adultos y adultos mayores de un mismo núcleo familiar, esto con el fin de encontrar puntos de confluencia entre las diferentes narrativas. También se entrevistó a la hermana Maritze Trigos, acompañante del proceso de AFAVIT, desde finales de la década de 1990; Carlos Ulloa, acompañante de familiares de víctimas de Trujillo entre 1997 y 1999; artistas locales, como Javier Naranjo y Ancízar Cano; estudiantes; profesores; comerciantes y políticos del municipio. Del mismo modo, se entrevistaron familiares de víctimas que se distanciaron de AFAVIT e iniciaron un proceso de evocación de sus seres queridos por cuenta propia. Asimismo, se realizaron múltiples entrevis-

11. Los archivos digitales y sistematizados del proceso de AFAVIT reposan en el Centro de Documentación Huellas de Vida. Allí, se han recopilado, clasificado y sistematizado los casos, hechos y circunstancias que rodean la masacre. Esta base de datos, ha sido insumo para el esclarecimiento histórico de la verdad. 
tas a visitantes/turistas que se acercaron al Parque-Monumento, motivados por el interés que despierta el lugar como referente de la memoria. Así, se recolectaron, codificaron y analizaron, individual y colectivamente, las maneras como se piensa, apropia y construye el Parque-Monumento.

\section{¿Por qué desde el patrimonio cultural?}

La Carta de Nara (1994) sostiene que la conservación del patrimonio, en todas sus formas y períodos históricos, encuentra su justificación en los valores que las comunidades atribuyen a los bienes tangibles e intangibles. En este sentido, las investigaciones realizadas desde un enfoque patrimonial permiten reconocer los puntos de confluencia entre objetos y sujetos en ámbitos relacionales de corte social, cultural y económico (Frondizi, 1972; Manzini, 2011; Prats, 1998). Así, la interpelación eficaz del patrimonio "debe mejorar la experiencia del visitante y aumentar el respeto y la comprensión social del significado del lugar, y de la importancia de su conservación" (Perichi, 2011: 33) 12 .

Ahora bien, la valoración de los bienes patrimoniales ha cambiado, por "el devenir de la historia, las modas y el propio dinamismo de las sociedades" (Llull, 2005: 179). En la Edad Antigua, el patrimonio era indicador de poder, lujo y prestigio, las colecciones eran heredadas y utilizadas para el disfrute individual de las élites. Más adelante, griegos y romanos exhibieron, en museos y cámaras de maravillas, bienes conservados por su importancia estética y pedagógica. En el Renacimiento, los nobles almacenaron objetos con valores históricos, decorativos y rememorativos (Lourés, 2001).

En el siglo XIX y principios del XX, eran valorados y conservados aquellos bienes materiales que representaban, socioculturalmente, los principios de una nación: bibliotecas, monumentos y archivos fueron utilizados por los Estados para objetivar la memoria de los ciudadanos (Achugar, 2003). Después de la segunda Guerra Mundial (1945-1980), las nuevas políticas públicas permitieron mayor accesibilidad a los bienes culturales con potencial socioeducativo, económico y cultural. El patrimonio se convirtió, rápidamente, en un elemento esencial para: "la emancipación

12. La significación cultural vincula "las etapas de la vida histórica de un bien patrimonial que permite comprender su razón de ser en el tiempo, detectar lo que es importante en la vida de los mismos y explicarlo como producto cultural. La importancia de su estudio radica en que se encuentra vinculado al valor del patrimonio. La pérdida y /o desconocimiento del significado asociada a la obsolescencia o abandono funcional de los bienes, contribuye a la desvalorización de los mismos, lo que favorece a la desprotección y pérdida del patrimonio cultural" (Manzini, 2011: 28). 
intelectual, el desarrollo cultural y la mejora en la calidad de vida de las personas" (Llull, 2005: 199).

En la década de los ochenta, diferentes proyectos políticos emprendieron una cruzada por democratizar la cultura; la aceptación de la diversidad y el reconocimiento de los derechos sociales puso en crisis "los valores unívocos occidentales tradicionalmente relacionados con el patrimonio cultural" (Perichi, 2011: 26). La participación, la plena accesibilidad y los aportes a la democracia fueron los nuevos referentes en las revaloraciones del patrimonio cultural; de esta manera, los colectivos asumieron un compromiso ético por conservar, gestionar y proyectar los bienes y las prácticas que los identifican (García-Canclini, 1999).

Los procesos de memorialización hacen parte de este último período: iniciativas enmarcadas en un patrimonio memorial que recoge "la significación política e identitaria, así como el trabajo del dolor, el conflicto y el olvido, constituyendo nuevas dimensiones de un patrimonio ligado al pasado y a su memoria" (Mora, 2013: 199). En este sentido, el patrimonio memorial se establece en los marcos sociales de la memoria, condición que determina las relaciones entre lugar, patrimonio e identidad. Así, los valores patrimoniales se asignan, socialmente, desde consensos, pero también desde disensos, lecturas sociales inscritas en los marcos del lenguaje, el tiempo y el espacio (Halbwachs, 2004).

Los memoriales democráticos son parte de la memorialización; estas representaciones simbólicas reflejan las relaciones emotivas y afectivas que existen entre comunidad y lugar, son espacios habitados y abiertos a nuevas apropiaciones y significaciones, lo que garantiza una activa y efectiva participación de familiares de víctimas, comunidades locales, grupos de derechos humanos y visitantes (IPPDH, 2012). El Parque-Monumento es un memorial democrático donde participan distintas voces; asimismo, el lugar resulta de la reflexión, comunicación y condena de la masacre, por tal motivo, los emprendedores de la memoria han utilizado el sitio para promover valores democráticos que condenan la violación de los derechos humanos.

Las prácticas de recordación $\mathrm{y}$, con ellas, los memoriales democráticos, se enmarcan en una serie de tensiones propias de las políticas de la memoria, lo que genera diferentes valoraciones. Por un lado, se identifican los valores positivos que funcionan como componentes básicos de la identidad colectiva, "estos valores dan cohesión al cuerpo social y sirven de respaldo para su sentido de pertenencia" (Perichi, 2011: 28). Algunos de los valores positivos que emanan del Parque-Monumento son los valores históricos, de uso, pedagógicos, sociales y simbólicos, atributos que se obtienen a partir de los trabajos de la memoria que emprenden familiares de víctimas, grupos de derechos humanos y visitantes (Jelin, 2002). 
Pero ¿cómo identificar estos valores? El Consejo Internacional de Monumentos y Sitios (ICOMOS), en sus diferentes asambleas, han propuesto una serie de insumos para el estudio, la documentación y la protección de sitios patrimoniales. Así, la Carta de Burra (1999) incita a la investigación y descripción de las asociaciones, los significados, las prácticas y las funciones de los sitios de significación cultural ${ }^{13}$. A partir de esta lectura, es posible reconocer los referentes históricos, las relaciones entre comunidad y lugar, y los múltiples valores que manifiestan un sitio de interés patrimonial (Consejo Internacional de Monumentos y Sitios (ICOMOS), 1999).

Así, para algunos habitantes del municipio, el Parque-Monumento es un referente simbólico que representa un pasado negativo. El lugar se enmarca en un contexto económico, social y político donde las causas que dieron origen a la masacre continúan vigentes, por tal motivo, sectores conservadores y grupos neoparamilitares que permanecen en la región miran con recelo estas iniciativas. Estos valores negativos limitan los trabajos de la memoria y, además, la proliferación de los antivalores pone en riesgo la continuidad del memorial ${ }^{14}$.

Por lo anterior, los valores patrimoniales no son "homogéneos, ni permanentes, ni socialmente objetivos", tampoco son un código binario estático; por el contrario, los bienes y las manifestaciones culturales están cargados de múltiples valores que cambian, históricamente, por las constantes transformaciones sociales, así como por los mecanismos de transmisión y comunicación que tiene cada sociedad (Perichi, 2011: 26). A continuación, se realizará una breve descripción de los valores positivos y negativos que emanan del Parque-Monumento, atributos sugeridos por familiares de víctimas, grupos de derechos humanos, habitantes del municipio, sectores políticos y visitantes.

13. Las asociaciones son las conexiones especiales que existen entre la gente y un sitio. Estas asociaciones pueden incluir valores sociales o espirituales, y responsabilidades culturales que asumen las comunidades en pro de conservar un sitio de significación cultural (ICOMOS, 1999).

14. Estas relaciones generan un patrimonio incómodo o negativo que se produce a partir de una memoria social negativa: "Se vincula a hechos traumáticos, de carácter conflictivo. Su gestión es compleja, principalmente porque suele estar asociado a ideologías y memoria (pasado reciente). Por otra parte, muchos estados no desean que sus territorios sean identificados con un patrimonio de este tipo, por lo que lo relegan a un segundo plano mientras ponen en valor otro tipo de patrimonio más aceptado socialmente" (Llanos, 2013:9). 


\section{Muros que guardan la memoria: reivindican las huellas de vida, que hacen eco de proyectos y luchas}

La proliferación y demarcación de una serie de lugares pensados para salvaguardar los testimonios de las víctimas son fenómenos que caracterizan los escenarios de reparación simbólica en Colombia ${ }^{15}$. En estos lugares, los dolientes de la violencia encuentran un espacio donde tramitar sus duelos, pedir justicia y, en ocasiones, evitar que los acontecimientos violentos se repitan. En este contexto, se piensa y construye el Parque-Monumento ubicado en Trujillo, Colombia, lugar inmerso en las tensiones y dinámicas de la memorialización.

Durante 2018, en medio de la peregrinación nacional al Parque-Monumento, el religioso Javier Giraldo señaló lo siguiente: "Trujillo refleja todos los males de Colombia". La frase sintetizaba la historia política, social y económica de una población desarraigada, fragmentada y desplazada por la violencia. Trujillo, Bolívar y Riofrío fueron escenarios del conflicto armado entre los años 1986 y 1994, cuando grupos paramilitares, en concomitancia con agentes estatales, narcotraficantes, terratenientes, facciones políticas y comerciantes, torturaron, asesinaron y desaparecieron un total de 342 personas (CNRR, 2008).

Uno de los males que sugiere el religioso Javier Giraldo es el uso y la tenencia de la tierra. A finales del siglo XIX e inicios del XX, la colonización antioqueña se expandió por los departamentos de Caldas, Valle del Cauca, Risaralda, Quindío y Tolima. El paso de los colonos por estos departamentos generó tensiones de diversa índole: la ubicación entre zona plana o de ladera fue uno de los conflictos más distintivos de la época (Palacios, 2011). La ubicación geográfica, la fertilidad de sus tierras y la variedad en los pisos térmicos motivaron el arribo de colonos a Trujillo' ${ }^{16}$, donde las disputas por la tierra no se hicieron esperar, pues fundadores, propieta-

15. La Ley 1448 de 2011 (Congreso de la República de Colombia, 2011) regula los procesos de reparación simbólica en Colombia. Esta normativa establece medidas judiciales, administrativas, sociales y económicas -individuales y colectivas- en beneficio de las víctimas que sufrieron daños como consecuencia de infracciones al Derecho Internacional Humanitario o violaciones graves y manifiestas a las normas internacionales ocurridas con ocasión del conflicto armado interno. En el Artículo 69, se establecen las medidas de reparación, restitución, indemnización, rehabilitación, satisfacción y garantías de no repetición, en sus dimensiones individuales, colectivas, materiales, morales y simbólicas. El Artículo 141 define la reparación simbólica de la siguiente manera: "toda prestación realizada a favor de las víctimas o de la comunidad en general que asegure la preservación de la memoria histórica, la no repetición de los hechos victimizantes, la aceptación pública de los hechos, la solicitud de perdón público, el establecimiento de la dignidad de las víctimas y la difusión de la verdad”.

16. Trujillo se encuentra ubicado en la ladera oriental de la Cordillera Occidental, en la trifurcación andina, y sus suelos son utilizados para el cultivo permanente, el levante de ganado bovino, el cultivo silvopastoril, la silvicultura y la vocación forestal. El área rural está compuesta por 36 barrios y la zona rural, por 10 
rios-hacendados y terratenientes avivaron conflictos que alcanzaron su clímax en la década de los cincuenta (Molano, 2015).

El bipartidismo es otro de los males que sugiere la metáfora del religioso Javier Giraldo. En los años cuarenta e inicios de los cincuenta, los pleitos electorales y la tenencia de la tierra agudizaron las contradicciones entre liberales y conservadores. Trujillo, al igual que otros municipios del territorio nacional, se encontraba en medio de un fuego cruzado, donde facciones de los dos partidos utilizaron los asesinatos selectivos, las conversiones forzadas, los enfrentamientos armados, los desplazamientos y las masacres como mecanismos para controlar el poder local (CNRR, 2008: 91).

En Trujillo, chulavitas, contrachusmeros y pájaros conformaron una contrainsurgencia nativa, que utilizó las armas y las urnas para desplazar y asesinar las vertientes liberales del municipio. Después de "limpiar", los conservadores no llegaron a ningún acuerdo, e iniciaron una disputa interna por el control político y territorial (Atehortúa, 1995) ${ }^{17}$. En relación con la violencia bipartidista, es necesario recalcar la responsabilidad del Partido Conservador en la organización y promoción de cuadrillas o policías cívicos: asesinos, fanáticos y clericales que anticiparon la formación de grupos paramilitares (Palacios, 2012) ${ }^{18}$.

En la década de los setenta e inicios de los ochenta, se forjaron asociaciones campesinas que contradecían las lógicas tradicionales, y eran lideradas por grupos de izquierda, sectores del liberalismo y fracciones de la Iglesia católica (Molano, 2015). Los campesinos de diferentes partes del país sintieron atracción por las iniciativas cooperativistas propuestas por la Asociación Nacional de Usuarios Campesinos de Colombia, ANUC ${ }^{19}$; la Unión de Trabajadores de Colombia, UTC; el Instituto Mayor Campesino, IMCA, y la Federación Agraria Nacional, FANAL.

corregimientos y 39 veredas, dedicadas a la producción de café, cacao, yuca, plátano, sorgo, mora, limón, caña de azúcar y caña panelera.

17. En Trujillo, a través del clientelismo, las armas y las urnas, se consolidó un poder gamonal conservador, con políticos que incidieron en el devenir de la masacre, entre ellos se encuentran: Leonardo Espinosa, León María Lozano, José Ríos, Baldino Giraldo, César Tulio Delgado, Rodrigo Lloreda Caicedo, Humberto González Narváez, Diego Garcés Giraldo y Rogelio Rodríguez (CNNR, 2008: 92).

18. Para Daniel Pécaut (2015), la influencia de los partidos tradicionales en la formación de las fuerzas militares y policivas corresponde al "civilismo", concepto que reflexiona acerca del predominio de las élites civiles sobre las instituciones militares, donde el Estado relega el monopolio de la fuerza a particulares. La Comisión Nacional de Reparación y Reconciliación (2008), se refiere a este fenómeno a partir del dominio indirecto del Estado: confluencia entre aparatos estatales de seguridad, grupos locales en el poder y narcotraficantes.

19. En 1968, el expresidente Carlos Lleras Restrepo formalizó la ANUC, organización que tenía por objetivo la redistribución de la tierra, a través de una reforma agraria; sin embargo, las iniciativas de la 
En 1985, el padre Tiberio Fernández consolidó 45 cooperativas campesinas, basadas en los principios de la ANUC y del IMCA. Las élites regionales criticaron fuertemente estas iniciativas, e iniciaron una campaña de desprestigio y persecución a sindicalistas, campesinos y obreros. Para los sectores conservadores de la sociedad trujillense, el modelo cooperativista tenía una estrecha relación con los movimientos de izquierda que proliferaban en el mundo. Así, terratenientes y gamonales justificaron la violencia, a través de una lógica contrainsurgente que tenía sentido en el contexto internacional, pero que era una lectura inadecuada en el ámbito local (Atehortúa, 1995) ${ }^{20}$.

La aparición de grupos guerrilleros es otro de los males que señala Javier Giraldo. A las tensiones entre movimientos sociales y élites regionales, se sumó la presencia paulatina de comisiones políticas y militares del Ejército de Liberación Nacional, ELN. El grupo guerrillero se ubicó en el Cañón de Garrapatas, punto geoestratégico que permitía la movilidad entre El Dovio, El Cairo y Trujillo. Asimismo, en 1987, el Movimiento Jaime Bateman Cayón, disidencia del Movimiento 19 de abril (M-19), ocupó varios territorios en el Valle del Cauca, entre ellos, Trujillo, Bolívar y Riofrío. Los dos grupos guerrilleros utilizaron el secuestro y la extorsión como mecanismos de control territorial y político: entre los secuestrados, asaltados y extorsionados, se encontraban familiares cercanos a los narcotraficantes Diego Montoya y Henry Loaiza.

El narcotráfico fue otro de los males que irrumpió social, política y económicamente los municipios de Trujillo, Bolívar y Riofrío. La bonanza cocalera en el Putumayo, a principios de los ochenta, generó una expansión territorial, de ahí la llegada de narcotraficantes al Valle del Cauca, punto geoestratégico para la comercialización

Asociación se truncaron por las visiones conservadoras de los terratenientes (Molano, 2O15). En 1972, el gobierno de Misael Pastrana suspendió la personería jurídica de la ANUC, argumentando infiltraciones guerrilleras; así, los terratenientes utilizaron la fuerza para reprimir las movilizaciones campesinas. En el Valle del Cauca, los corteros de caña materializaron las propuestas de la ANUC, e iniciaron la toma de tierras con la consigna: "la tierra pa'l que la trabaja" (Wills, 2015).

20. A finales de los ochenta e inicios de los noventa, el mundo atestiguó la caída de la URSS y, en consecuencia, el fin de la Guerra Fría. En el marco del conflicto bipolar, el Estado colombiano orbitó bajo las tendencias de Estados Unidos, en una lucha contrainsurgente que se manifestó en la firma de acuerdos internacionales, como el Tratado Interamericano de Asistencia Recíproca (1947), la Alianza para el Progreso (1961), la Doctrina de Seguridad Nacional y el Estatuto de Seguridad (Decreto 1932 de 1978, y que duró hasta 1982). En Latinoamérica, el Instituto Hemisférico para la Cooperación en Seguridad o Escuela de las Américas, situada en la zona del Canal de Panamá, materializó la lucha contrainsurgente adiestrando a 60 ooo militares y policías que, a nivel estratégico, incluyeron a la población civil como objetivo militar; asimismo, utilizaron la tortura y la violación de derechos humanos en pro de la "seguridad nacional". En relación a la masacre de Trujillo, se ha establecido que el mayor Alirio Antonio Urueña Jaramillo recibió entrenamiento, por parte de Estados Unidos, en la Escuela de las Américas; siendo el militar con mayor rango que participó, directamente, en la masacre (CNRR, 2008: 183). 
de la droga. En el Parque-Monumento, se encuentra una vitrina con diferentes objetos, entre ellos una chiva o bus escalera, transporte utilizado en zonas rurales. La chiva fue elaborada por familiares de víctimas, en un ejercicio por reconocer y denunciar los perpetradores de la masacre, en este caso, se denuncia la participación del narcotraficante Henry Loaiza Ceballos (alias "el Alacrán”), quien comenzó como ayudante, luego como conductor y terminó como propietario de una flota de chivas. "El Alacrán” y Diego León Montoya (alias “Don Diego") se beneficiaron con la bonanza cocalera, e iniciaron la compra de terrenos en la zona rural de Trujillo.

Cada día las tensiones eran más fuertes: una bomba de tiempo estaba a punto de estallar. El ELN se radicalizó, e inició el secuestro y asesinato de militares y familiares de narcotraficantes, acciones bélicas que despertaron en la región las represalias enunciadas en el Plan Democracia, el Plan Repliegue y el Plan Pesca (CNRR, 2008). El 27 de octubre de 1988 y el 29 de abril de 1989, se realizaron dos marchas campesinas lideradas por la ANUC, y su pliego de peticiones era claro: mejoras en los servicios públicos, arreglo de vías, dotación en las escuelas y nombramiento de profesores, entre otras. A la segunda marcha asistieron los transportadores de jeeps, el padre Tiberio y las organizaciones campesinas lideradas por el párroco. Esta marcha fue estigmatizada por el gobernador Ernesto González Caicedo, quien, junto a la Policía y el Ejército, condenaron la movilización como una acción subversiva del ELN.

Así, bajo una lógica contrainsurgente, los participantes de la marcha fueron tildados de guerrilleros, lo que aceleró la alianza entre fuerzas militares, grupos paramilitares, élites regionales y narcotraficantes ${ }^{21}$. Esta alianza cegó la vida de 342 personas ${ }^{22}$. Trujillo y sus alrededores sufrieron ocho años de secuestros, ejecuciones extrajudiciales, desapariciones forzadas, asesinatos selectivos y torturas (Sánchez,

21. El modelo de paramilitarismo surgió en el Magdalena Medio, más exactamente en Puerto Boyacá. Estructuras contrainsurgentes, conformadas por estamentos militares (Batallón Bárbula y Brigada XIV), la Asociación Campesina de Agricultores y Ganaderos del Magdalena Medio (ACDEGAM), la multinacional Texas Petroleum Company, políticos de la derecha radical aglutinados en el Movimiento de Restauración Nacional (MORENA), y la Sociedad Colombiana de Defensa de Tradición, Familia y Propiedad (TFP), compuesta por periodistas y juristas que elevaron su discurso en defensa de la lucha antisubversiva a nivel nacional. Este modelo se replicó en varias regiones del país, con acciones bélicas en Urabá, Córdoba, Segovia, la Rochela y Pueblo Bello (Medina, 1990).

22. El número de víctimas está sujeto al actor que enuncia y tipifica los actos violentos (Torres, 2017). La Comisión Nacional de Reparación y Reconciliación (2008) determina la conexión entre hechos, por lo tanto, reconoce la relación entre los asesinatos, desapariciones, secuestros y torturas llevadas a cabo entre 1986 y 1994 . El Estado solo ha reconocido 34 víctimas, aquellas que fueron asesinadas entre marzo y abril de 1990: el padre Tiberio y sus acompañantes, los ebanistas y los habitantes de la Sonora. Para familiares de víctimas y grupos de derechos humanos existe continuidad y conexión entre hechos, por lo tanto, aluden al asesinato y desaparición de 342 personas. Esta disputa por el pasado afecta, directamente, a familiares de víctimas, porque niega el derecho a la verdad, justicia y reparación (CNRR, 2008). 
2014). Muchos de los hechos centrales de la masacre se consumaron en las haciendas Las Violetas y Villa Paola, de Diego Montoya y Henry Loaiza, respectivamente (CNRR, 2008: 146).

El control territorial fue el objetivo real de la masacre, la lucha contrainsurgente era solo un pretexto. Los narcotraficantes actuaron desde su condición de propietarios de tierras y exportadores de drogas; en ambos casos, tras la ausencia estatal y la ilegalidad de su labor, nació un especial interés en la creación de estructuras militares que brindaran seguridad en las propiedades, los laboratorios y en las rutas hacia el Océano Pacífico. Así, los narcotraficantes aprovecharon las estrategias contrainsurgentes que desplegaba el ejército, y se sumaron a las mismas, a su manera, sembrando el miedo y terror a través de secuestros, torturas, homicidios, desapariciones forzadas y desplazamientos (CNRR, 2008).

El Primer Informe de Memoria Histórica, de la Comisión Nacional de Reparación y Reconciliación (2008), designa como masacre lo sucedido en Trujillo, Bolívar y Riofrío. Las masacres son homicidios intencionales de cuatro o más personas en iguales circunstancias de modo, tiempo y lugar. Esta masacre tenía una triple función: i) preventiva, que busca garantizar el control de la población, las rutas y los territorios; ii) punitiva, que expresa un castigo ejemplar a los que cuestionan la hegemonía o el estado de las cosas; y iii) simbólica, que exhibía la capacidad del victimario de romper barreras éticas, normativas y religiosas (CNRR, 2008).

Después de la masacre, la impunidad marcó los procesos judiciales, pues los testigos oculares habían sido asesinados, algunos victimarios habían sido absueltos y otros condenados por homicidio con fines terroristas o por la conformación de autodefensas y grupos sicariales. En vista de esto, y orientados inicialmente por el religioso Javier Giraldo, los familiares de víctimas decidieron enviar el caso a la Organización de los Estados Americanos, OEA, con el fin de determinar el papel y la responsabilidad del Estado antes, durante y después de la masacre (Comisión Intercongregacional de Justicia y Paz (CIJP), 1998) ${ }^{23}$. En esta instancia, la Comisión Interamericana de Derechos Humanos, $\mathrm{CIDH}$, creó la Comisión de Investigación de los Sucesos Violentos de Trujillo (CISVT-1994), conformada por diferentes instituciones del ámbito nacional: delegados de instituciones cívicas, religiosas y no gubernamentales. En enero de 1995, la CIDH arrojó el informe final con 200 páginas

23. En 1994, el religioso Javier Giraldo llegó a Trujillo como líder de la Comisión Intercongregacional de Justicia y Paz; él, con la ayuda de los artistas Carlos Ulloa y Stella Guerra, documentaron decenas de casos que permitieron hacer un llamado al Colectivo de abogados José José Alvear Restrepo e iniciar, de este modo, los procesos jurídicos. Las desapariciones, los asesinatos y las acciones violentas presentadas, indistintamente, por familiares de víctimas confluyeron en una línea común, lo que despertó el debate en torno a la secuencialidad de los actos. 
que contenían 12 conclusiones y 9 recomendaciones, responsabilizando al Estado colombiano por acción y omisión.

El gobierno de Ernesto Samper asumió la responsabilidad por 34 casos, reconocidos bajo la culpabilidad del Estado. A partir de las recomendaciones hechas por la Comisión Interamericana de Derechos Humanos, se construyó el Parque-Monumento ${ }^{24}$. En 1998, el arquitecto colombiano Santiago Alberto Camargo, con diseños elaborados a partir de las expectativas enunciadas por los trujillenses, inició la construcción (Silva; Martínez, 2014). El memorial democrático refleja la lucha que, por 20 años, han adelantado familiares de víctimas y grupos de derechos humanos, por conservar un espacio que permita narrar, denunciar y evidenciar el pasado trágico y el presente impune. Así, la memoria en los muros expresa, de manera pedagógica, el rostro de las víctimas, los victimarios, los referentes históricos que posibilitaron la masacre, la solidaridad entre pares, la inoperancia estatal, la impunidad jurídica y política, y la exigencia en derechos, como proyecto que fortalece los procesos de democratización en un puente que une pasado, presente y futuro.

En este sentido, el valor histórico es el primer atributo del Parque-Monumento, una cualidad otorgada por habitantes del municipio, visitantes y sectores académicos. Allí, se territorializaron las memorias de la violencia política, social y económica que afectó a Trujillo y pueblos aledaños. El lugar es una huella que aporta un conocimiento histórico acumulativo de la violencia colombiana, el lugar es el resultado de las reflexiones que giran en torno a la masacre, sus muros albergan los sentidos, significados y sentimientos de los testigos de la violencia, que, a través de sus testimonios, guardan la memoria: reivindican huellas de vida y hacen eco en proyectos y luchas. Así, el Parque-Monumento es un recordatorio que se constituye en un marco social de la memoria, para eso se construyó: para mostrar lo que sucedió, quiénes lo hicieron, con qué saldos y, a partir de ahí, tratar de generar estrategias de no repetición.

24. Los procesos de reparación simbólica están asociados al modelo de justicia restaurativa, que tiene como propósito reconciliar a las víctimas y los victimarios a través del resarcimiento de los daños ocasionados, tanto material como simbólicamente (Tavera, 2017). En este panorama, se inscribe el Parque-Monumento; sin embargo, este lugar ha sido objeto de ataques por parte de grupos neoparamilitares, lo que dificulta las prácticas de recordación. Asimismo, como señala el informe de la Comisión Nacional de Reparación y Reconciliación (2008), la reparación simbólica en Trujillo es problemática porque fue utilizada como "mecanismo para debilitar el reconocimiento de otros deberes del estado, tales como el deber de hacer justicia, el de establecer la verdad de lo sucedido y el de reparar de manera integral" (CNRR, 2008: 293). 


\section{Somos semilla, somos memoria, somos el sol que renace ante la impunidad}

En el patrimonio cultural, el valor de uso se refiere a las cualidades del bien, en tanto sirve para hacer algo o da satisfacción a las necesidades humanas (Ballart, 2007). Así, la reconstrucción del tejido social, la elaboración de los duelos y el desarrollo de una pedagogía de la memoria son ejes centrales que determinan los valores de uso en el memorial democrático.

Por un interés académico, me acerqué a Trujillo en 2016. Al llegar al municipio, un lugar colorido adornaba su cabecera, era el Parque-Monumento, construcción que representaba el sentir de familiares de víctimas y grupos de derechos humanos. Después de instalarme en el hotel, me dirigí al memorial, le pedí indicaciones a un habitante del municipio y me contestó con disgusto e ironía: iva al entierro del municipio, allá solo entierran plata! No entendí lo que decía y, en el momento, no le di importancia. Al llegar al Parque-Monumento, me sorprendí: esculturas, flores, árboles, caminos, frutas, pancartas, fotografías y dibujos adornaban el lugar. El buen estado de los espacios y de los objetos me causaba curiosidad, todo parecía nuevo, intacto, colorido, agradable a la vista. Mientras veía las pinturas, dos jóvenes se acercaron y sugirieron caminar por el parque.

En el recorrido, mencionaron las partes que configuran el lugar, los hechos que lo precedieron, los espacios y sus significados. Mi primera visita duró varios días y, después, en 2017, regresé en dos oportunidades y, en 2018, realicé una visita más prolongada. Al llegar al municipio, era recibido por las matriarcas que integraban AFAVIT, en cada visita conocía personas nuevas y, con ellas, nuevas historias. Adultos, jóvenes, adolescentes y niños frecuentaban el lugar, la relación entre ellos era amena, fraterna, de compadrazgo y hasta de familiaridad; es curioso, porque la masacre pretendió destruir el tejido social, pero, allí, una organización sólida contradecía las intenciones de los violentos ${ }^{25}$. Ahora bien, al conocer la organización entendí que los valores de uso del Parque-Monumento eran comprensibles si se reconocían las personas que día a día habitaban el espacio, es decir, a AFAVIT y a los acompañantes del proceso.

En 1994, la llegada del religioso Javier Giraldo a Trujillo despertó el interés por saber qué había pasado, por qué había pasado y quiénes habían sido los responsables.

25. El informe de la Comisión Nacional de Reparación y Reconciliación (2008), Trujillo, una tragedia queno cesa, señala las siguientes consecuencias del designio criminal: desplazamientos, desarraigo de pobladores, destrucción de núcleos familiares, muertes por pena moral y desarticulación de organizaciones campesinas. En este sentido, la masacre atacó, fragmentó y deshiló las relaciones cotidianas que habitantes de Trujillo, Bolívar y Riofrío habían construido durante décadas. 
Así, en 1995, nació AFAVIT, con la asesoría de la Comisión Intercongregacional de Justicia y Paz, CIJP. Los objetivos de la asociación eran los siguientes: exigir justicia, realizar veeduría al Estado, forjar una comunidad de duelo, y acompañar jurídica y psicológicamente a los dolientes (Centro de Investigación y Educación Popular (CINEP 2014; Silva; Martínez, 2013; Torres, 2017). Sin embargo, al pasar los años, y en vista del panorama desolador de impunidad y revictimización, la comunidad de duelo transitó hacia una comunidad en exigencia de derechos (CINEP, 2014: 72).

AFAVIT, con el acompañamiento del religioso y de los artistas Carlos Ulloa y Stella Guerra, reunió los testimonios de campesinos, amas de casa, estudiantes, comerciantes y artesanos ${ }^{26}$. Las discusiones del pasado nutrieron los procesos de memorialización; en este sentido, familiares de víctimas y grupos de derechos humanos forjaron una comunidad de memoria que reconocía un pasado común y una identidad compartida. Así, las relaciones simbólicas y materiales definieron las bases, los vínculos y las redes que sostienen y mantienen la comunidad. Por lo tanto, el Parque-Monumento se consolidó como un espacio de identificación, que fortalece y preserva la memoria. Fiestas, viajes, peregrinaciones, talleres, encuentros entre integrantes, conversaciones cotidianas y relaciones afectivas fortalecieron los hitos y las huellas de unidad, que se acercaban a senderos de verdad, justicia y reparación. Ahora bien, estos lazos de fraternidad y complicidad generaron un "nosotros" y un "ellos", que, en ocasiones, difieren de las percepciones del pasado, el presente y de los posibles futuros.

Para recuperar la memoria individual y social del municipio, se realizaron talleres, reuniones y conversatorios que buscaban responder las siguientes preguntas: ¿qué pasó?, ¿por qué pasó?, ¿dónde, cómo y cuándo?, y ¿quiénes fueron los responsables?, mientras que las respuestas se expresaban a través de dibujos, poemas, biografías, fotografías, canciones y esculturas ${ }^{27}$. La mayoría de representaciones hablaban de las víctimas, quiénes eran y qué hacían, como una forma de dignificar y traer al presente a los ausentes, lo que adquiere mayor peso en el caso de los desaparecidos. Los testigos y, con ellos, los testimonios fundamentaban la naciente comunidad, sus

26. En Trujillo, después de la masacre, la comunidad de memoria recolectó, por medio de talleres, reuniones y conversatorios, las historias de lo sucedido. Con la información de los testimonios, AFAVIT conformó el Centro Documental Huellas de Vida, que reposa en el Parque-Monumento. El 25 de agosto de 2012, el centro documental recibió un premio internacional de derechos humanos, por parte del Ayuntamiento de Asturias, España.

27. Las reuniones entre familiares de víctimas y acompañantes religiosos se realizaban en diferentes lugares: la plaza central, casas, el Colegio Julián Trujillo, la iglesia, la Junta de Acción Comunal y los Altos de Tómeles: "en ese entonces asistía mucha gente", pero los espacios eran muy reducidos: "El Parque se construye debido a la necesidad que nosotros como familiares de víctimas teníamos para tener un sitio" (Matriarca de AFAVIT, comunicación personal, 15.12.2017). 
narraciones permitieron conocer las características de la masacre, responsabilizar a los victimarios y asumir una posición política y social frente a lo sucedido ${ }^{28}$. Así, las memorias de la violencia, el papel del padre Tiberio Fernández, las identidades campesinas, y las exigencias de justicia, reparación y verdad fueron los engranajes que dieron cuerpo a la comunidad.

Para la comunidad de memoria era necesario narrar su pasado a través de diferentes vehículos, entre ellos un memorial que permitiera mostrar simbólica y pedagógicamente las reflexiones acerca de la masacre (Silva; Martínez, 2013). Así, como parte de la condena que profirió el $\mathrm{CIDH}$, el Estado indemnizó a las víctimas $\mathrm{y}$, con este dinero, AFAVIT compró seis hectáreas de terreno en la ladera norte del municipio y, en 1998, iniciaron la construcción del Parque-Monumento. Los encuentros para decidir qué, cómo y dónde construir, las ollas comunitarias mientras se limpiaba el rastrojo de la montaña, la elaboración de los osarios, la exposición de los objetos personales de las víctimas, el guidismo, la limpieza y el mantenimiento del lugar sugieren un sentido de identidad y pertenencia, que se construye de manera cotidiana (McDowell, 2008).

Por lo atroz e impune de la masacre, la comunidad de memoria consideró que el monumento no debía ser inerte. El lugar tenía que representar el sentir de las víctimas, en un compromiso constante por elaborar, reelaborar y apropiar el pasado. En este sentido, el Parque-Monumento se pensó y construyó como lugar abierto a nuevas significaciones; espacio comunitario, donde se exhibirían y guardarían objetos, testimonios y fotografías de las víctimas. Así, se consolidó un lugar donde, finalmente, las víctimas pudieron ser escuchadas, narrar sus experiencias y ser identificadas como comunidad (CNRR, 2009).

Haber participado en la planeación y elaboración del memorial fue un avance en términos de reparación: "una de las políticas de conservación de memoria que se desarrolla de parte de las víctimas circula en torno a la elaboración del duelo como el horizonte de sentido desde el que consideran debe adelantarse la reconstrucción de memoria histórica" (CNRR, 2008: 205). A través del memorial, familiares de las víctimas pudieron catalizar sur dolor, reinvertirlo y, en ocasiones, superarlo ${ }^{29}$. En este

28. Las narrativas de las víctimas se constituyen a partir del deber de la memoria; en este sentido, los testigos reclaman un lugar en la historia, consolidando una "subjetividad rememorante" que cuestiona el pasado, combate los olvidos, exige justicia y avala proyectos democráticos (Garzón, 2015: 119).

29. Los duelos afectan las dimensiones físicas, afectivas, emocionales y espirituales de los dolientes, y son procesos que se dan a nivel personal o social. El dolor emocional que genera la pérdida de un ser querido se expresa según el vínculo afectivo con el ausente (CIJP, 1998). Los duelos son heridas que deben ser cerradas mediante un proceso que permita aceptar y experimentar el dolor de la pérdida, adaptarse al ambiente en el que falta el ser querido, retirar la energía emocional y reinvertirla en nuevas relaciones sociales; por lo tanto, la elaboración de los duelos requiere de protección, apoyo y resistencia (Jung, 1972). 
proceso, se utilizaron diferentes mecanismos, como encuentros con otras víctimas, peregrinaciones, aproximaciones al arte, y el acompañamiento por parte de grupos de derechos humanos, religiosos y visitantes (Martínez; Silva, 2014).

Ahora bien, la masacre de Trujillo se caracterizó por la desaparición y fragmentación de los cuerpos, lo que dificulta una "adecuada elaboración del duelo por parte de los familiares" (Cortés, 2007: 197) ${ }^{30}$. Los cuerpos son parte fundamental en la etapa que tiene que ver con la aceptación de la pérdida: "la presencia del cuerpo físico es un catalizador de los procesos de duelo (...) el cuerpo ratifica la muerte del ser querido y permite aceptar que no va a regresar" (Mariño, 2011: 145). En el Parque-Monumento, referentes simbólicos, como osarios, árboles, escritos, esculturas, bancas de madera y pinturas sirven como referentes catárticos y liberadores que suplen la presencia física de los cuerpos. En los ejercicios cartográficos, los referentes de mayor enunciación fueron la representación del padre Tiberio Fernández, las actividades económicas que realizaban las víctimas antes de la masacre, los osarios y los objetos dejados por los visitantes en un acto de solidaridad y reconocimiento.

En el Parque-Monumento hay entierros simbólicos de personas ajenas a la asociación. Este es el caso de Edilia Payan, mamá de Jhonathan Alberto Uscátegui Payán, desaparecido el $10^{\circ}$ de septiembre de 2004. Con la asesoría de familiares de víctimas, Edilia sembró un árbol que sirvió como herramienta para afrontar la tristeza y aceptar los hechos. Lo anterior muestra uno de los atributos que tiene el memorial, como lugar abierto a nuevas apropiaciones y significaciones.

El Jardín de Chilito es otro entierro simbólico que se encuentra en el lugar. Alba Mery Chilito es la mamá de Francy Chilito, asesinada en 1990. A Chilito, como le decían de cariño, la asesinaron bandas emergentes de paramilitares, el 7 de febrero de 2013. Los victimarios únicamente cambiaron de nombre, y su permanencia en el municipio opaca liderazgos, reprime la tramitación pública de los duelos y revictimiza a la sociedad, silenciando y ocultando lo sucedido (CNRR, 2008; CINEP, 2014). Estos entierros simbólicos son muestra de tres factores característicos de la comunidad de memoria: solidaridad, creatividad y la lucha constante contra la impunidad. El arte es una de las herramientas más utilizadas por familiares de víctimas y grupos de

30. La desaparición forzada, como modalidad de la violencia, permite ocultar las magnitudes de los hechos, porque la ausencia de los cuerpos disminuye y encubre al victimario, aumenta la impunidad y reduce la presión política por la violación a los derechos humanos (CNRR, 2008). Asimismo, la desaparición forzada es un mecanismo de terror que genera incertidumbre y tortura psicológica en los familiares de las víctimas, el anhelo por ver de nuevo al ausente se convierte en algo letal. En Trujillo, siete personas han muerto de pena moral, casos que, para el CNRR, derivan del hecho violento. 
derechos humanos como medio de denuncia, tramitación de duelos, visibilización de los hechos y construcción colectiva de la memoria (Córdoba, 2014) (1. $^{31}$

Los familiares de víctimas han utilizado el arte para expresar lo que no pueden decir con palabras, acercando al visitante, de una manera apacible, a la realidad de la masacre. El torso desmembrado del padre Tiberio Fernández es un ejemplo de estas representaciones: tejido, dibujado, esculpido y tallado se encuentra en diferentes partes del memorial. Esta representación iconográfica condensa la crueldad de la masacre y la degradación del ser humano; sin embargo, el visitante que desconoce lo sucedido relaciona la imagen con Jesucristo, iconografía apacible por su naturalización. Al preguntar por el significado del torso, los familiares de víctimas mencionan el uso del terror durante la masacre, responsabilizan a los victimarios y terminan reconociendo la importancia del párroco como líder social y moral. Así, este referente simbólico se convierte en un vehículo de la memoria utilizado por los familiares de víctimas y grupos de derechos humanos para recordar, denunciar y exigir justicia.

\section{Huellas de memoria y dignidad, pasos de resistencia y esperanza}

El valor simbólico o comunicativo del patrimonio cultural se determina a partir de los signos y símbolos que utilizan las sociedades humanas para la comunicación (Ballart, 2007). Así, la dimensión simbólica es un valor representativo que expresa de forma sintética la relación entre ideas y valores, reconocidos por la conciencia y determinados por la identidad de cada colectividad (Prats, 1998). En este sentido, el Parque-Monumento es un vehículo portador de las memorias que testigos y dolientes de la violencia han construido, un referente que busca incidir política y socialmente en el presente, mientras su valor simbólico se desprende del mensaje que contienen los signos y los símbolos que transitan a través de los espacios y objetos creados por familiares de víctimas y grupos de derechos humanos.

"Al principio no teníamos nada, tampoco teníamos un lugar donde reunirnos, donde escucharnos, donde consolarnos"(Matriarca de AFAVIT, comunicación personal, 30.08.2016). Familiares de víctimas y grupos de derechos humanos reconocen

31. Luego del episodio violento, viene el momento de explicar qué pasó, por qué paso y quiénes fueron los responsables. La primera información que se extrajo, recolectó y organizó se hizo a través de escenarios judiciales y académicos imprescindibles para establecer autores y motivaciones. Sin embargo, estos sectores emanan un discurso técnico e impasible, que no contribuye a la superación del dolor emocional que sufre la víctima. Así, en el arte es posible trascender los espacios donde la acción comunicativa resulta limitante (Villaveces-Izquierdo, 1997). 
la importancia del Parque-Monumento desde la planeación, pues ellos, a través de talleres, asambleas y reuniones fueron quienes decidieron qué se debía construir y cómo se iba hacer. Con la asesoría del arquitecto Santiago Camargo, realizaron una maqueta con cinco áreas dedicadas a la tramitación de los duelos, la reflexión de los hechos, la construcción de la memoria y la proyección del municipio.

Para la comunidad de memoria era necesario construir un espacio dónde enseñar y analizar las causas y consecuencias de la masacre. En este sentido, se construyó el área de los hechos, un lugar donde se denuncia la impunidad, se reconocen victimarios y víctimas, y se muestra el proceso adelantado por AFAVIT, que busca, en sus acciones, justicia, verdad y una reparación oportuna. En este lugar, se encuentran referentes simbólicos que permiten determinar por qué, cómo, para qué y quiénes participaron en la masacre (CIJP, 1998). El espacio lo conforman mapas, fotografías, elementos característicos de las víctimas, pinturas, documentos de las cooperativas y el Centro Documental Huellas de Vida.

El área de entierro es la representación simbólica más referenciada en las cartografías: "lugar de duelo, lugar de memoria, lugar de peregrinación". Allí se encuentran 235 osarios, 66 de ellos contienen restos de las víctimas, mientras que en los otros solo hay objetos personales. Estas esculturas fueron el primer testimonio público en el proceso de recuperación y representación de la masacre, elaboradas por familiares de víctimas con asesoría de artistas y grupos de derechos humanos.

Los osarios son un referente significativo de apropiación y apego que permite "re-dignificar a sus desaparecidos y muertos hablando de quiénes eran ellos y cuál era su rol dentro de la comunidad" (Romero, 2011). Asesorados por Adriana Lalinde, familiares de víctimas se convirtieron en "artistas para reivindicar en barro la historia de sus seres queridos" (Mariño, 2011: 201). Son esculturas que simbolizan las víctimas con datos específicos, como nombre, fechas, profesiones y tipo de muerte (desaparición forzada o asesinato). Las esculturas se caracterizan por representar a las víctimas en su cotidianidad: campesinos, ebanistas, estudiantes, amas de casa y religiosos, mostrar quiénes eran; es un trabajo que busca reivindicar la memoria de las víctimas, "es limpiar el nombre de los ausentes", cambiando la versión que los violentos utilizaron para justificar sus acciones ${ }^{32}$. En vista de las tensiones que generan el pasado y sus usos, el nombre de este lugar ha cambiado y ahora se llama "lugar de vida", haciendo referencia a la vida más allá de la muerte, es decir, las

32. Para la Comisión Nacional de Reparación y Reconciliación (2009), estas representaciones corresponden a "las memorias que exaltan las identidades borradas por la guerra". El conflicto armado en Colombia ha desdibujado el rostro y la identidad de las víctimas, pues en términos de justificar los actos violentos resulta más sencillo culpar a las víctimas, desconociendo su procedencia (Mariño, 2011). 
víctimas están vivas en la memoria de familiares y visitantes, que asumen el mensaje como un compromiso ético, de rechazo y reproche a la violencia.

En el área de entierro se pretendía construir varias fuentes para simbolizar la vida que renace después de la muerte. Asimismo, la maqueta tenía diferentes lugares, como el espacio iconográfico, el templete, la plaza ceremonial y el campanario, los cuales tenían por objetivo la tramitación y superación de los duelos, a partir del recuerdo, la reflexión, la retroalimentación de la memoria y la consolidación de nuevos planes de vida; sin embargo, por problemas presupuestales, aún no se han construido. Para la comunidad de memoria esto genera cierta preocupación, pues sienten que la tarea aún está inconclusa y, por ende, sus proyecciones e ilusiones se centran en la culminación del memorial como fue pensado y plasmado en la maqueta: "si no lo construimos nosotros, nuestros hijos lo construirán o ustedes, alguien debe terminar el parque" (Matriarca de AFAVIT, comunicación personal, 13.12.2017).

Otra de las áreas del memorial es la de siembra. Puesto que la mayoría de víctimas eran campesinos, se pensó en un lugar donde fuera posible reconstruir los lazos de vecindad quebrantados por la masacre. En el Parque-Monumento, los árboles, frutales y jardines son elementos que permiten, a familiares de víctimas, un retorno mediado a la noción de campesino, de ahí la importancia que tiene la tierra: cilantro, aguacates, plátanos, mazorca, limones y naranjas son sembrados por familiares de víctimas, alimentos que después recogen y reparten entre miembros de la comunidad. Por tanto, la responsabilidad por cuidar la vegetación del memorial es tema central en las reuniones de AFAVIT: "las flores muestran vida y abundancia, para que no se muestre más la muerte, ihay vida!, sembramos a nuestros familiares y recibimos sus frutos" (Patriarca de AFAVIT, comunicación personal, 15.12.2017).

En el espacio del área de memoria, se encuentra el muro a la Sombra del Amor, construido por el escultor Kurdo Hoshayar Rasheed. El muro tiene siete nichos con objetos enviados por personas de otros países, siendo una representación de solidaridad, justicia y reconocimiento (Mariño, 2011). El lugar ha sufrido varios atentados, entre ellos una ráfaga de disparos que acabó con los nichos de vidrio, dejando una marca que evidencia las dificultades que asume la comunidad de memoria y sus trabajos, en un territorio donde el pasado no pasa (Huyssen, 2002). En el área de la memoria también se encuentra el mausoleo del padre Tiberio Fernández, donde reposa la siguiente frase: "Si mi sangre contribuye para que en Trujillo amanezca y florezca la paz que tanto anhelamos, gustosamente la derramaré". En relación al padre Fernández, vale la pena mencionar el proyecto ¡Tiberio Vive Hoy! Testimonio de Vida de un Mártir, libro escrito por la comunidad e incluido por la UNESCO en el Registro de Memorias del Mundo, que busca asegurar la preservación del patrimonio documental de importancia nacional y regional. 
En el área de historia y utopía, se pensó construir un puente de Tarabita, el Reloj del siglo XXI, el Jardín de esculturas, la Torre mirador utopías al siglo XXI, la Plaza nunca más, la Plataforma de Promesas, y el Camino de las flautas, lugares propuestos por la comunidad para relacionar la masacre de Trujillo con fenómenos similares del contexto nacional e internacional. No obstante, en la actualidad, solo se ha construido el Sendero nacional e internacional de la memoria, camino que conecta diferentes puntos, memorias de resistencia y lucha que asumen diferentes comunidades en Colombia y el mundo: "En el Sendero nacional de la memoria decimos que la memoria de Colombia camina por Trujillo, caminamos porque las víctimas sigan vivas, seguimos exigiendo verdad, justicia y reparación. Caminamos porque la vida con dignidad lo exige, caminamos como un derecho, un deber, un compromiso y una exigencia" (Matriarca de AFAVIT, comunicación personal, 31.08.2016).

Para los familiares de víctimas y grupos de derechos humanos, el Parque-Monumento no podía ser inerte. Los incumplimientos del Estado en relación a la reparación moral, económica y judicial hicieron del memorial un lugar de denuncia, expresión que pone en discusión los problemas actuales del municipio. En la actualidad, se realizan diferentes actividades, entre ellas el seguimiento, por parte del Programa de las Naciones Unidas para el Desarrollo, PNUD; además, funciona un jardín de Bienestar Familiar. Asimismo, el lugar se convirtió en un referente turístico para Trujillo, apreciado por unos y señalado por otros. En el memorial se realizan cursos de costura, enfermería, cocina e informática; se cultiva, se reflexiona acerca del pasado, y se proponen alternativas al presente. En este sentido, el memorial democrático se ha convertido en una huella de memoria y dignidad, que día a día da pasos de resistencia y esperanza.

\section{La memoria revela lo indigno, reconstruye la verdad y exige justicia}

El valor pedagógico es otro referente característico del Parque-Monumento. Para familiares de víctimas y grupos de derechos humanos, es necesario que los visitantes conozcan qué sucedió; por lo tanto, las experiencias de las víctimas y las problemáticas actuales del municipio son exhibidas en analogía a la violación de derechos humanos. En este ejercicio, se utilizan diferentes vehículos de la memoria, como fotografías, libros, obras de arte y archivos. Estas representaciones sensibilizan al visitante, forjando una conciencia colectiva que subvierte los discursos totalizantes, abre nuevos espacios deliberativos, valida las voces silenciadas y funciona como 
recurso contra el olvido (Caballero, 2014). Así, los trabajos de la memoria son un imperativo moral que reorientan el pensamiento y la acción para que no se repita la barbarie, pues "la memoria no es solo traer a la conciencia de las generaciones posteriores hechos que ocurrieron en el pasado. Para eso está la historia. La memoria es una exigencia moral con carga política" (Reyes, 2005: 37).

El salón Galería de la Memoria Tiberio Fernández es el lugar más utilizado por la comunidad. Allí, todos los días se realizan diferentes actividades: talleres, cursos de cocina, informática y enfermería, catequesis, novenas y reuniones con organismos estatales. El salón cuenta con los instrumentos necesarios para el desarrollo de actividades pedagógicas: sillas, mesas, video-beam, computadores y tableros. Adicionalmente, cada semana, acompañantes del proceso dictan talleres de derechos humanos a niños y jóvenes pertenecientes a la asociación. Para la comunidad de memoria estos niños y jóvenes son el eje central en la construcción de un futuro más justo. En la actualidad, el Grupo Infantil Jimmy García Peña y el Grupo Juvenil Huellas de Vida están articulados a AFAVIT. Ellos, a través de poemas, canciones, dibujos, coplas, libros y danzas representan las memorias de la masacre; sin embargo, estos ejercicios no se quedan en el dolor, por el contrario, buscan promover los derechos humanos, dignificar la vida y aceptar las diferencias (Sacavino, 2015).

Por otro lado, los recorridos orientados por familiares de víctimas al interior del Parque-Monumento generan un mayor grado de sensibilidad en los visitantes. Los memoriales democráticos tienen la particularidad de enseñar, activa y participativamente, "la teoría y la practica: lo ético y lo político; lo ético y lo estético; lo micro y lo macro, en formas de habitar la corporeidad, los territorios y los vínculos en una construcción dialéctica" (Ortega; Castro; Merchán; Vélez, 2015: 15).

El Parque-Monumento funciona como una estrategia de pedagogía pública, porque en sus muros se reconocen a las víctimas y victimarios, se confronta la historia oficial que negó la existencia de los mismos, se vincula el pasado y el presente en un ejercicio por promover los derechos humanos, se desarrolla una memoria crítica desde los testimonios, se forja un pensamiento reflexivo que contribuye al empoderamiento de las víctimas en un proceso por construir una sociedad justa, inclusiva y democrática (Herrera, 2017). El Parque-Monumento transmite un mensaje y, a su vez, empodera a las víctimas en términos de reclamación de derechos, de un nunca más, como partícipes de un proyecto político que revela lo indigno, reconstruye la verdad y exige justicia. 


\section{¡Va al entierro del municipio, allá solo entierran plata!}

La comunidad de memoria, a través de sus trabajos, ha logrado construir un lugar de diálogo que identifica el sentir de las víctimas; sin embargo, de allí se desprenden diversas valoraciones, incluso contradictorias entre sí, puesto que dependen del grado de subjetividad (Perichi, 2011). Así, emergen los antivalores o valores negativos, percepciones externas, que contrastan con los valores positivos que la comunidad de memoria atribuye al Parque-Monumento.

Los valores negativos critican la existencia del memorial, por "ser una inversión innecesaria, por manchar la historia del pueblo, por enterrar la plata o por ser un lugar improductivo" (Comerciante de Trujillo, comunicación personal, 12.12.2018). El religioso Javier Giraldo lo explica de la siguiente manera: "lamentablemente AFAVIT es como un precioso jardín rodeado por un gran pantano. No se percibe en el resto de la población trujillense, y menos en sus autoridades, ninguna solidaridad con las víctimas sino más bien molestia y repulsa frente a la afirmación de la memoria" (CINEP, 2014: 6).

De lo anterior se desprenden varios factores a tener en cuenta. El primero tiene que ver con las contramemorias que, para el antropólogo uruguayo Hugo Achugar (2004), resultan de la indiferencia de los procesos comunicativos de los monumentos, pues no se puede pretender una única narrativa del pasado y, de ser así, se procede a "objetivar la memoria"; en este sentido, "la visibilidad del monumento vuelve invisible todo aquello y a todos aquellos que el monumento niega o contradice" (Achugar, 2004: 135).

En Trujillo, las contramemorias impugnan los trabajos emprendidos por AFAVIT, ya que, para varios sectores del municipio, las posturas críticas de la Asociación subvierten el orden establecido, pues en Trujillo las vertientes conservadoras que hicieron parte activa de la masacre aún ostentan el poder político, un poder que se hereda y es utilizado para mantener el statu quo. A este factor, se suma la negación del conflicto armado, lo que rechaza el trabajo emprendido por víctimas y grupos de derechos humanos, en una lógica donde los altos grados de impunidad y la presencia de los victimarios generan un temor latente que se agudiza con los actos violentos perpetrados después de la masacre ${ }^{33}$. Así, las interpretaciones y reinterpretaciones

33. El libro Trujillo, la otra versión, del Centro de Investigación y Educación Popular (2014), denuncia la reactivación de la masacre, donde "desde el 2000 se ha reeditado la misma barbarie y crueldad que rigió entre 1986 y 1994” (CINEP, 2014: 200). En este sentido, la tragedia continúa, los grupos paramilitares retornaron al municipio y ahora mutaron en Los Rastrojos, autodefensas que amenazan, asesinan y desaparecen a las personas que opinan diferente. Ahora bien, las exigencias de las víctimas son un compromiso moral que convoca el pasado en función del presente, porque, como sugiere Reyes-Mate (2005: 27), si todo se olvida, ¿qué impide que los crímenes se repitan?: "La prueba más contundente del poder de los 
de lo sucedido generan un "escenario de luchas de sentido, de definición de distintos 'nosotros' y de competencias entre distintas memorias" (Jelin; Langland, 2003:11).

En Trujillo, es común escuchar que AFAVIT monopolizó la memoria de la masacre, que malgasta o entierra el dinero en el memorial y que son los únicos dueños del Parque-Monumento. Siguiendo la línea de Achugar, la enunciación -o "lugar de donde se habla"- es un factor importante de la monumentalización. En Trujillo, AFAVIT ha sido la voz con mayor eco, por ende, su gestión ha sido fuertemente criticada, pues, sin querer, opaca otras iniciativas que se han forjado en el municipio. Otro factor a tener en cuenta es el generacional: "la presencia de nuevos sujetos y la redefinición de escenarios y marcos interpretativos traerán nuevos sentidos 'a veces inclusive contrarios a los originarios'” (Jelin; Langland, 2003:3). En este caso, jóvenes del municipio han utilizado el Parque-Monumento para consumir alucinógenos, pasar un rato en pareja o expresar sus afinidades con los equipos de fútbol. En relación a los valores patrimoniales, cabe resaltar que las reinterpretaciones del memorial son naturales en una sociedad dinámica, por lo tanto, "los valores cambian históricamente, tanto por las constantes transformaciones sociales como por mecanismos comunicacionales" (Perichi, 2011: 27).

Otro aspecto importante es el olvido. Para algunos habitantes del municipio, el Parque-Monumento trae recuerdos que no permiten una convivencia pacífica, de ahí la necesidad por liberar ese pasado doloroso. La politóloga española Paloma Aguilar (2008), citando a Nietzsche, señala que "el conocimiento del pasado es sólo deseable si es útil para el futuro y el presente, no si debilita el presente o erradica un futuro" (35). En esta medida, el olvido puede desempeñar una función terapéutica necesaria para no vivir estrechamente del pasado. Así, el Parque-Monumento, como referente geográfico, demarcado en el territorio, impide que los habitantes del municipio olviden, trayendo al presente recuerdos considerados negativos: "en esta situación hay un doble peligro: el de un exceso de pasado en la repetición ritualizada, en la compulsión que lleva al acto, y el de un olvido selectivo, instrumentalizado y manipulado" (Jelin, 2002: 14).

Así, el proceso de reparación simbólica en Trujillo se enmarca en un contexto social y político donde las causas que produjeron el conflicto armado siguen vigentes. La permanencia de grupos paramilitares, la indiferencia de algunos habitantes, y las tensiones entre memoria oficial y memoria comunitaria generan una memoria

terroristas no está en sus pistolas, ni en el número de efectivos o en la determinación de matar, sino en el olvido, es decir, en esta especie de consenso social según la cual hay que pasar la página, hay que seguir viviendo, hay que hacer que todo siga en normalidad. Esta frivolización de las vidas de los muertos es el mayor triunfo de las pistolas; un triunfo que es una batalla interpretativa del pasado. Primero se mata físicamente a la víctima y luego se le hace hermenéuticamente irrelevante" (27). 
en disputa (Pollak, 2006). Estas condiciones limitan los trabajos de la memoria, convirtiendo las narrativas de las víctimas en memorias subterráneas que no pueden decir lo que quieren decir, o no todo lo pueden contar en el ámbito público, sino que es una memoria que se encuentra en la "frontera de lo decible y lo indecible, lo confesable y lo inconfesable" (Pollak, 2006: 24).

A modo de conclusión, se puede decir que los memoriales democráticos utilizados en escenarios fuertemente golpeados por la violencia adquieren su significación cultural a través de los valores otorgados por las comunidades que se identifican con la representación simbólica. Las herramientas de valoración que brinda el patrimonio cultural permiten investigar, organizar y analizar las particularidades de estos lugares, reconociendo en ellos valores de uso, valores sociales, valores pedagógicos y valores simbólicos. Asimismo, es necesario reconocer la valoración como parte del proceso de la patrimonialización o institucionalización del patrimonio, lo que permite su conservación y transmisión.

Estas construcciones, al ser elaboradas de manera colectiva, despiertan sentidos de pertenencia y apropiación que se reflejan en la conservación y transmisión de los bienes. En el caso de Trujillo, el Parque-Monumento, como lugar de significación cultural, es una riqueza participacionalista que permite la construcción de una comunidad de memoria. El lugar se distancia de las lógicas estatales de monumentalización, porque familiares de víctimas, grupos de derechos humanos y visitantes dan sentido y significación al mismo. Existe una relación de apego entre comunidad de memoria y lugar, lo que permite su conservación y preservación; este apego simboliza el sentir, la conciencia y el sentido de pertenencia de una sociedad que representa su pasado, en un ejercicio por enseñar y dialogar acerca de lo que no puede volver a ocurrir.

Las representaciones simbólicas construidas a partir de las memorias de las víctimas muestran los procesos de duelo, justicia, resistencia y no repetición: osarios, galerías, fotografías, jardines, pinturas, poemas, canciones, biografías y el centro de documentación son referentes simbólicos utilizados para significar el pasado, afrontar los desafíos del presente y reflexionar acerca del futuro. En este sentido, el Parque-Monumento es variable, no viene dado, no es definido y está siempre en un proceso de construcción y reconstrucción. Por último, los trabajos de la memoria suponen una serie de tensiones o luchas políticas por el sentido del pasado conflictivo (Aguilar, 2008). Así, la continuidad de la violencia, la impunidad estatal y las valoraciones negativas de los habitantes del municipio convierten el pasado de las víctimas en memorias subterráneas que emergen cuando es posible, cuando sienten confianza y el contexto lo permite. 


\section{Referencias}

Achugar, Hugo (2003). El lugar de la memoria, a propósito de los monumentos (Motivos y paréntesis). En Monumentos memoriales y marcas territoriales (pp. 191-214), editado por Jelin Elizabeth; Victoria Langland. Buenos Aires: Siglo XXI.

Achugar, Hugo (2004). Planetas sin boca: escritos efimeros sobre arte, cultura y literatura. Montevideo: Ediciones Trilce.

Aguilar, Paloma (2008). Políticas de la memoria y memoria de la política. El caso español en perspectiva comparada. Madrid: Alianza Editorial.

Allier, Eugenia; Crezel, Emilio (eds.) (2015). Las luchas por la memoria en América Latina. Historia reciente y memoria política. México: UNAM/Instituto de Investigaciones Sociales.

Atehortúa, Adolfo. (1995). El poder y la sangre, las historias de Trujillo, Valle. Bogotá: Cinep/ Pontificia Universidad Javeriana.

Ballart, Josep (2007). El patrimonio histórico y arqueológico: valor y uso. Barcelona: Ariel.

Barbuto, Valeria (2012). Los sitios de la memoria en la agenda de la democracia. Red Universitaria sobre Derechos Humanos y Democratización para América Latina, 3, 125-137.

Bickford, Louis; Brett, Sebastián; Ríos, Marcela; Ševčenko, Liz (2007). Memorialización y Democracia. Políticas de Estado y Acción Civil. Santiago de Chile: Flacso/ICTJ/International Coalition of Sites of Conscience.

Brodsky, Carla (2012). Memoria y Monumento. El memorial en la recuperación de la historia de la represión 1973-199o en Chile (Tesis de licenciatura). Universidad de Chile, Facultad de Artes, Departamento de Teoría e Historia del Arte, Santiago de Chile.

Caballero, Luis (2014). Los museos de la memoria como posibilidad de reflexión ético-política. Ciudad Paz-Ando, 7(1), 126-145.

Centro de Investigación y Educación Popular (2014). Trujillo, la otra versión. Bogotá: Códice.

Choay, François (2007). Monumento y Monumento Histórico. En Alegoría del patrimonio (724). Barcelona: Gustavo Gili

Comisión Intercongregacional de Justicia y Paz (1998). Parque por la Vida, la Justicia y la Paz. Monumento a las Víctimas de los Hechos Violentos de Trujillo, 1987-1994. Bogotá: Códice.

Comisión Nacional de Reconciliación y Reparación (2008). Trujillo una tragedia que no cesa: Primer Informe de Memoria Histórica de la Comisión Nacional de Reparacióny Reconciliación. Bogotá: Planeta. 
Comisión Nacional de Reconciliación y Reparación (2009). Memorias en Tiempo de Guerra, repertorio de iniciativas. Bogotá: Punto Aparte Editores.

Congreso de la República de Colombia (10 de junio de 2011). Ley 1448 de 2011: Por la cual se dictan medidas de atención, asistencia y reparación integral a las víctimas del conflicto armado interno y se dictan otras disposiciones. Recuperado de https://www.unidadvictimas.gov.co/ sites/default/files/documentosbiblioteca/ley-1448-de-2011.pdf

Consejo Internacional de Monumentos y Sitios (1999). Carta de Burra, Carta de ICOMOS Australia para Sitios de Significación Cultural. Cuba Arqueológica. Recuperado de http:// www.cubaarqueologica.org/document/carta14.pdf.

Córdoba, Diana (2014). Aportes de las artes plásticas/visuales en procesos de sensibilización, reparación simbólica y construcción de la memoria. Magdalenas por el cauca, cartografias de la memoria y cuerpos gramaticales (Tesis de licenciatura). Universidad Pedagógica Nacional, Facultad de Bellas Artes, Bogotá.

Cortés, Catalina (2007). Escenarios de terror entre esperanza y memoria: políticas, éticas y prácticas de la memoria cultural en la costa pacífica colombiana. Antípoda, 4, 11-27.

Cuervo, José (2002). Una aproximación desde el habitar a la vivienda compartida en Niquitao, Medellín. Cuadernos de vivienda y urbanismo, 2, 38-71.

Dogliani, Patrizia (2009). La memoria pública de la Segunda Guerra Mundial en Europa. En El Estado y la Memoria: gobiernos y ciudadanos frente a los traumas de la historia (151-210), editado por Ricard Vinyes. Buenos Aires: Del Nuevo Extremo.

Espinosa, Rodolfo; Rubio, Julio; Uribe, Hernando (2013). Pensar, sentir y vivir los espacios: una propuesta de educación geografica, formación ciudadana y apropiación del lugar. Cali: Universidad del Valle.

Fabri, Silvana (2013). Lugares de memoria y marcación territorial: sobre la recuperación de los centros clandestinos de detención en Argentina y los lugares de memoria en España. Cuadernos de Geografía, 22(1), 93-108.

Fernández, Roberto (2015). Lugares de memoria de la dictadura en Chile: memorialización incompleta en el barrio Cívico de Santiago. Bitácora Urbano Territorial, 1(25), 131-136.

Frondizi, Risieri (1972). ¿Qué son los valores? México: FCE.

García-Canclini, Néstor (1992). Culturas Híbridas. Estrategias para entrary salir de la modernidad. Buenos Aires: Suramericana.

García-Canclini, Néstor (1999). Los usos sociales del patrimonio cultural. En Patrimonio etnológico: nuevas perspectivas de estudio (pp. 16-33), coordinado por Encarnación Aguilar. Sevilla: Junta de Andalucía/Instituto Andaluz del Patrimonio Histórico 
Garzón, María (2015). La subjetividad rememorante. Revista Colombiana de Sociología, 38(2), 115-137.

Guixé, Jordi (2007). El memorial democrático y los lugares de la memoria: la recuperación del patrimonio memorial en Cataluña. Entelequia, 7, 217-228.

Halbwachs, Maurice (2004. Los marcos sociales de la memoria. Barcelona: Anthropos.

Heidegger, Martin. (2014). Construir, habitar, pensar. Fotocopioteca, 39. Recuperado de http:// www.lugaradudas.org/archivo/publicaciones/fotocopioteca/39_heidegger.pdf

Herrera, Martha (junio, 2017). Lugares de la memoria como escenarios para una pedagogía pública. Palabras almargen, 106. Recuperado de http://www.palabrasalmargen.com/index. php/articulos/nacional/item/lugares-de-la-memoria-como-escenarios-para-una-pedagogia-publica?category_id=138.

Huyssen, Andreas (2002). En busca del futuro perdido. Cultura y memoria en tiempo de globalización. México: FCE.

Huyssen, Andreas (2014). Memorias crepusculares: la marcación del tiempo en una cultura de amnesia. Buenos Aires: Prometeo Libros.

Instituto de Políticas Públicas en Derechos Humanos del Mercosur (2012). Principios fundamentales para las políticas públicas sobre sitios de memoria. Buenos Aires: IPPDH.

Jaramillo, Jefferson (2015). Las comisiones de estudio sobre la violencia en Colombia. Un examen a los dispositivos y narrativas oficiales sobre el pasado y presente de la violencia. En Las luchas por la memoria en América Latina. Historia reciente y violencia política (pp. 247-273), editado por Eugenia Allier; Emilio Crenzel. México: UNAM/Instituto de Investigaciones Sociales.

Jelin, Elizabeth (2002). Los Trabajos de la Memoria. Buenos Aires: Siglo XXI.

Jelin, Elizabeth; Langland, Victoria (2003). Monumentos, memoriales y marcas territoriales. Madrid: Siglo XXI.

Jung, Carl (1972). El secreto de la flor de oro. Buenos Aires: Paidós.

Llanos, Eva (2013). La gestión de los espacios de la memoria: el caso de Belchite (Tesis de maestría). Universidad de Valladolid, Escuela Universitaria de Ciencias Empresariales y del Trabajo, Valladolid.

Llull, Josué (2005). Evolución del concepto y de la significación social del patrimonio cultural. Arte, Individuo y Sociedad, 17, 175-204.

Lourés, María (2001). Del concepto de monumento histórico al de patrimonio cultural. Ciencias Sociales, Revista de la Universidad de Costa Rica, 94, 141-150. 
Manzini, Lorena (2011). El significado cultural del patrimonio. Estudios del Patrimonio Cultural, $6,27-42$.

Marín, Jefferson (2011). "Deber de memoria” y "razones de olvido" en la justicia transicional. Análisis Político, 71, 129-147.

Mariño, María (2011). Sangre de mártires, semilla de esperanza: construcción de las nociones de cuerpo y memoria tras la masacre de Trujillo. Bogotá: Editorial Universidad del Rosario.

Martínez, Catalina (2012). Memorialización y Políticas Públicas de la Memoria en Bogotá: Centro del Bicentenario de Memoria, Pazy reconciliación (Tesis de licenciatura). Pontificia Universidad Javeriana, Facultad de Ciencias Sociales, Departamento de Antropología, Bogotá.

Martínez, Nathalia; Silva, Orlando (2013). Luchas políticas por la memoria del conflicto armado interno colombiano: el caso de la masacre de Trujillo. Bogotá: UD Editorial.

Martínez, Nathalia; Silva, Orlando (2014). Instituciones de memoria y marcas territoriales: "el caso del conflicto armado en Colombia”. Ciudad Paz-Ando, 7(1), 146-162.

Mate, Reyes (2005). A contraluz; ideas politicamente correctas. Barcelona: Anthropos.

McDowell, Sara (2008). Heritage, Memory and Identity. En The Ashgate Research Companion to Heritage and Identity (pp.37-53), editado por Brian Graham; Peter Howard. Recuperado de https://www.routledgehandbooks.com/doi/10.4324/9781315613031.ch2

Medina, Carlos (1990). Autodefensas, paramilitaresy narcotráfico en Colombia. Origen, desarrollo y consolidación. El caso de Puerto Boyacá. Bogotá: Documentos Periodísticos.

Messina, Luciana (2011). El ex centro clandestino de detención "Olimpo" como dispositivo de la memoria: Reflexiones sobre las marcas territoriales y sus usos. Aletheia, 2(3), 1-26.

Mills, Wright (1993). La imaginación sociológica. Madrid: FCE.

Molano, Alfredo (2015). Fragmentos de la historia del conflicto armado (1920-2010). En Contribución al entendimiento del conflicto armado (pp.541-598), compilado por Comisión Histórica del Conflicto y sus Víctimas. Recuperado de http://www.altocomisionadoparalapaz.gov. $\mathrm{co} /$ mesadeconversaciones/PDF/Informe\%20Comisi_n\%2OHist_rica\%2Odel\%20Conflicto\%2Oy\%2Osus\%2OV_ctimas.\%2OLa\%2OHabana\%2C\%2OFebrero\%2Ode\%2O2O15.pdf

Montañez, Gustavo; Delgado, Ovidio (1998). Espacio, territorio y región: conceptos básicos para un proyecto nacional. Cuadernos de Geografia, 1(2), 121-134.

Mora, Yaneth (2013). Lugares de Memoria: entre la tensión, la participación y la reflexión. Panorama, 7(13), 97-109.

Ortega, Piedad; Castro, Clara; Merchán, Jeritza; Vélez, Gerardo (2015). Pedagogía de la memoria para un país amnésico. Bogotá: Universidad Pedagógica Nacional. 
Palacios, Marco (2012), Violencia pública en Colombia, 1958-2010, Bogotá: Fondo de Cultura Económica.

Pécaut, Daniel (2015). Un conflicto al servicio del status quo social y político. En Contribución al entendimiento del conflicto armado en Colombia (pp.599-650), compilado por Comisión Histórica del Conflicto y sus Víctimas. Recuperado de http://www.altocomisionadoparalapaz. gov.co/mesadeconversaciones/PDF/Informe\%2OComisi_n\%2OHist_rica\%2Odel\%2oConflicto\%2Oy\%2Osus\%2OV_ctimas.\%2OLa\%2OHabana\%2C\%2OFebrero\%2Ode\%2O2O15.pdf

Perichi, Ciro (2011). Patrimonio Cultural, un enfoque diversoy comprometido. México: UNESCO.

Piper, Isabel (2009). Investigación y acción política en prácticas de memoria colectiva. En El Estado y la Memoria: gobierno y ciudadanos frente a los traumas de la historia (pp. 151-172), editado por Ricard Vinyes. Buenos Aires: Del Nuevo Extremo.

Pollak, Michael (2006). Memoria, olvido, silencio: la producción social de identidades frente a situaciones limite. Buenos Aires: La Margen.

Prats, Llorenç (1998). El concepto de patrimonio cultural. Política y Sociedad, 27, 63-67.

Raggio, Sandra (2017). Memoria de la Noche de los Lápices. Tensiones, variaciones y conflictos en los modos de narrar el pasado reciente. La Plata, Argentina: Universidad Nacional de La Plata.

Ricoeur, Paul (2008). La memoria, la historia, el olvido. Buenos Aires: FCE.

Rieff, David (2017). El elogio del olvido: las paradojas de la memoria histórica. Madrid: Debate.

Romero, Gabriel (2011). Mujeres del nunca más: la voz de la ausencia. Prismasocial, 7, 6-31.

Sacavino, Susana (2015). Pedagogía de la memoria y educación para el "nunca más" para la construcción de la democracia. FOLIOS, 41, 69-85.

Saldarriaga, Alberto (1998). Monumentos nacionales de Colombia. La huella, la memoria, la historia. Bogotá: El Ancora Editores.

Sánchez, Luz (2014). La lucha por la memoria colectiva en Trujillo, Valle del Cauca, Colombia en los años 2005-2010 (Tesis de maestría). Universidad de Palermo, Facultad de Ciencias Sociales, Buenos Aires.

Sierra, Yolanda (2014). Relaciones entre el arte y los derechos humanos. Derecho del Estado, $32,77-100$.

Martínez, Nathalia; Silva, Orlando (2013). Luchas políticas por la memoria del conflicto armado interno colombiano: el caso de la masacre de Trujillo. Bogotá: UD Editorial.

Strauss, Anselm; Corbin, Juliet (2002). Base de la investigación cualitativa: Técnicas y procedimientos para desarrollar la teoría fundamentada. Medellín: Universidad de Antioquia. 
Tavera, Esteban (2017). Hacemos memoria. Recuperado de http://hacemosmemoria. org/2017/05/o9/reparacion-simbolica-un-compromiso-que-va-mas-alla-de-los-monumentos/

Todorov, Tzvetan (200o). Los abusos de la memoria. Buenos Aires: Paidós.

Torres, Laura (2017). Narrativas de la memoria: el poder del lenguaje en la construcción de sentido después de una masacre. Memoria y Sociedad, 21(4), 21-37.

Traverso, Enzo (2007). El pasado: instrucciones de uso historia, memoria, política. Barcelona: Marcial Pons.

Tuan, Yi-Fu (1977). Espacio y Lugar. La perspectiva de la experiencia. Recuperado de https:// es.scribd.com/doc/6o894082/Espacio-y-Lugar-Yi-Fu-Tuan.

Villaveces-Izquierdo, Santiago (1997). Art and Mediation: Reflections on Violence and Representation. En Cultural Producer in Perilous States: Editing events, Documenting Change (pp. 233-254), editado por George Marcus. Chicago: University of Chicago Press.

Wills, María (2015). Los tres nudos de la guerra colombiana: un campesino sin representación política, una polarización social en el marco de una institucionalidad fracturada, y unas articulaciones perversas entre regiones y centro. En Contribución al entendimiento del conflicto armado en Colombia (pp. 1-41), compilado por Comisión Histórica del Conflicto y sus Víctimas. Recuperado de http://www.altocomisionadoparalapaz.gov.co/mesadeconversaciones/PDF/Informe\%2OComisi_n\%2OHist_rica\%2Odel\%2OConflicto\%2Oy\%2O sus\%2OV_ctimas.\%2OLa\%2OHabana\%2C\%2OFebrero\%2Ode\%2O2O15.pdf

Yory, Carlos (2002). Del monumento a la ciudad: el fin de la idea de monumento en el nuevo orden. Bogotá: Pontificia Universidad Javeriana.

Yory, Carlos (2003). Topofilia, Ciudady Territorio, una estrategia pedagógica de desarrollo urbano participativo con dimensión sustentable para las grandes metrópolis de América Latina en el contexto de la globalización, el caso de la ciudad de Bogotá (Tesis doctoral). Universidad Complutense, Facultad de Geografía e Historia, Madrid.

Young, James (2000). Cuando las piedras hablan. Los puentes de la memoria, 1, 80-94. 